\title{
Etnobotánica de plantas tóxicas en el partido de Vicente López (Buenos Aires, Argentina)
}

\author{
Ethnobotany of toxic plants in the district of Vicente López (Buenos Aires, Argentina) \\ Federico Valerio ${ }^{1,2}$, Anahí N. Herrera Cano ${ }^{1,3} \odot$ \& María E. Suárez ${ }^{1,2} \odot$
}

\begin{abstract}
Resumen: El objetivo de este trabajo fue realizar una primera prospección sobre la etnobotánica de plantas tóxicas en el partido de Vicente López (Buenos Aires, Argentina). Se trabajó con personas adultas que residen y/o trabajan en el área de estudio. La información y materiales se recopilaron mediante recorridos por la zona y entrevistas abiertas y semiestructuradas. Se identificaron 42 especies consideradas tóxicas, cuyas partes producen efectos variados y de distinta gravedad. El consenso sobre su toxicidad es en general bajo y el concepto vernáculo de tóxico no es univoco; la gente emplea diferentes criterios para clasificar a una especie como tóxica. Las actitudes ante las plantas tóxicas también varían. Los resultados están en concordancia con lo previsto para el conocimiento botánico urbano. La postura de quienes hacen un manejo consciente de estas especies, basado en sus conocimientos y en las particularidades del contexto, es la deseable para conservar la salud y la flora simultáneamente. Este trabajo provee una base para comprender las representaciones y percepciones locales sobre el tema, a partir de las cuales se pueden diseñar programas educativos, a la vez que aporta a la etnobotánica y disciplinas afines.
\end{abstract}

Palabras clave: Área Metropolitana de Buenos Aires, conocimiento botánico urbano, etnobiología, etnobotánica urbana, toxicología.

Summary: The purpose of this study was to carry out a first survey on the ethnobotany of toxic plants in Vicente López district (Buenos Aires, Argentina). The study was performed with adult men and women who live and/or work in the study area. Information and materials were gathered through visits to the surroundings, and open and semistructured interviews. A total of 42 species were considered toxic by the interviewees; their parts produce various effects of different severity. Consensus about their toxicity was generally low and the vernacular concept of toxic was not univocal; people use different criteria to classify a plant as toxic. Attitudes in relation to toxic plants also vary. The results agree with the predictions for urban botanical knowledge. The position of those who make a conscious management of these species, based on their knowledge and the particularities of the context, is the desirable one in order to simultaneously preserve human health and flora. This work provides a basis for understanding local representations and perceptions on the topic, from which educational programs can be designed, and contributes to ethnobotany and related disciplines.

Key words: Buenos Aires Metropolitan Area, ethnobiology, toxicology, urban botanical knowledge, urban ethnobotany.

${ }^{1}$ Grupo de Etnobiología, Departamento de Biodiversidad y Biología Experimental, Facultad de Ciencias Exactas y Naturales, Universidad de Buenos Aires, Intendente Güiraldes 2160, C1428EGA, Ciudad Autónoma de Buenos Aires, Argentina. E-mail: eugesuarez78@gmail.com

${ }^{2}$ Grupo de Etnobiología, Instituto de Micología y Botánica (INMIBO), Consejo Nacional de Investigaciones Científicas y Técnicas-Universidad de Buenos Aires, Intendente Güiraldes 2160, piso 4, Cl428EGA, Ciudad Autónoma de Buenos Aires, Argentina.

${ }^{3}$ Centro de Estudios Farmacológicos y Botánicos (CEFYBO), Consejo Nacional de Investigaciones Científicas y TécnicasUniversidad de Buenos Aires, Paraguay 2155, piso 16, C1121ABG, Ciudad Autónoma de Buenos Aires, Argentina. 


\section{Introducción}

La etnobotánica urbana tiene como particularidad que los contextos culturales donde se desarrolla son pluriculturales y complejos; por esto, el conocimiento botánico urbano (CBU) está constituido por un corpus heterogéneo, dinámico y adaptativo de saberes, concepciones y prácticas que guían acciones selectivas en el uso de las plantas, sus partes y productos derivados de ellas. Dichos saberes se originan de distintas fuentes, tienen distintas procedencias, y así el CBU incluye componentes notradicionales (p. ej. provenientes de medios de comunicación masivos o de la educación formal) y otros ligados a tradiciones (p. ej. costumbres familiares o tradiciones del lugar de origen de pobladores inmigrantes), que coexisten e interactúan en el mismo contexto pluricultural (Hurrell et Pochettino, 2014). Otra particularidad de estos contextos es que la flora exótica está muy presente, en especial al seno de los hogares y en la vía pública (cf. p. ej. Lahitte et al., 1999; Rovere et al., 2013; Roger et al., 2016). En Argentina, la etnobotánica urbana es una línea de reciente desarrollo y aún poco explorada. En la provincia de Buenos Aires, la mayoría de las investigaciones han sido llevadas a cabo en ciertos sectores del Área Metropolitana de Buenos Aires (AMBA), no habiendo antecedentes etnobotánicos específicos para partidos del noreste de la provincia (Hurrell, 2014; Hurrell et Pochettino, 2014).

El término tóxico suele utilizarse popularmente para referir a sustancias que provocan envenenamiento con resultados mayormente fatales (Schultes et al., 1998). A nivel académico, una de las definiciones más aceptadas hoy en día de plantas tóxicas es la que afirma que son aquellas especies que producen efectos adversos en el cuerpo humano y de otros animales (Huai, 2010). En la misma línea, se consideran toxinas a aquellos compuestos que tienen efectos negativos en el crecimiento, desarrollo o supervivencia de los organismos (Huai et Xu, 2000; Wittstock et Gershenzon, 2002). Al respecto, resulta importante estar al tanto de los saberes, percepciones y actitudes que poseen los habitantes en relación a estas especies, en especial porque los mismos determinan acciones concretas que, muchas veces por desconocimiento, pueden derivar en consecuencias perjudiciales para la salud de las personas o de los animales domésticos ( $\mathrm{p}$. ej. al desconocer cuáles son las plantas tóxicas con las que se convive y si la toxicidad es por tacto o consumo) y/o para la conservación de la flora local (p. ej. si la gente erradica plantas que cree que son tóxicas solo por temor) (Hurrell et Pochettino, 2014). Así, un estudio etnobotánico sobre plantas tóxicas puede aportar y es esencial para, por ejemplo, programas de difusión sobre la existencia e identidad de plantas tóxicas y de los cuidados que la gente debe tener para con las mismas que, en especial en ámbitos urbanos, resultan cruciales (Pérez Cuadra et al., 2012). Sin embargo, la etnobotánica de plantas tóxicas es un tópico poco desarrollado a nivel global y local. En el país, los trabajos etnobotánicos que tratan plantas tóxicas suelen enfocarse en aquellas nocivas para el ganado ( $p$. ej. Martínez et Luján 2011; Califano et Echazú, 2013), pero no en aquellas perjudiciales para la población humana.

Este trabajo tiene como objetivo realizar una primera prospección sobre la etnobotánica de las plantas tóxicas en el partido bonaerense de Vicente López. Se parte de la hipótesis de que la mayor parte de los conocimientos, por ser un contexto urbano, estarán en estrecha relación con los conceptos de la ciencia académica, particularmente con los de la toxicología y la botánica. Así, la presente contribución pretende: a) identificar las especies consideradas tóxicas y caracterizar los conocimientos vernáculos asociados a las mismas (nombres, partes tóxicas, mecanismos de acción y efectos asociados), y discutirlos en función de la información académica disponible sobre su toxicidad; b) dilucidar qué criterios de clasificación emplea la gente para definir a ciertas especies como tóxicas y contrastarlos con las definiciones de la toxicología; y c) analizar las actitudes y prácticas de las personas para con las plantas que consideran tóxicas en relación a la conservación de la flora y el resguardo de la salud. 


\section{Materiales y Métodos}

\section{Zona de estudio}

Vicente López es un pequeño partido de la provincia argentina de Buenos Aires con una superficie aproximada de $33 \mathrm{~km}^{2}$. Está localizado al norte de la Ciudad Autónoma de Buenos Aires, capital del país, y forma parte del AMBA, el aglomerado urbano más extenso y poblado de Argentina (Fig. 1). Por tanto, se trata de un contexto social pluricultural y complejo, donde convergen y cohabitan personas de distintos orígenes, historias, poblaciones y culturas, entre otros aspectos (Hurrell, 2014; Hurrell et Pocchettino, 2014; Observatorio AMBA, 2021). En términos biogeográficos, el área de estudio se localiza en la porción más austral de la ecorregión conocida como Delta e Islas del Paraná, que abarca el Delta del Paraná y el cauce del Río de la Plata (Fig. 1). La presencia de cuerpos de agua permanentes que caracterizan la región da como resultado un clima templado y húmedo, con poca amplitud térmica diaria y estacional, dando lugar a la presencia de comunidades y especies típicas de las ecorregiones subtropicales húmedas del noreste del país (Matteucci, 2012).

En el partido de Vicente López, el arbolado urbano está conformado mayoritariamente por especies exóticas como el "plátano" [Platanus $x$ acerifolia (Aiton) Willd.] o el "paraíso" (Melia azedarach L.) (Lahitte et al., 1998, 1999; Hurrell et Bazzano, 2003). De igual forma, las especies exóticas con valor ornamental destacan en los espacios domésticos, siendo muy frecuentes el "laurel de jardín" (Nerium oleander L.), "la costilla de Adán" (Monstera deliciosa Liebm.) o el "agapanto" [Agapanthus praecox subsp. orientalis (F. M. Leight.) F. M. Leight.], entre otras (Jankowski et al., 2000; Hurrell et Bazzano, 2003; Hurrell et al., 2005). Aun así, en sectores con menor intervención humana, como el área ribereña que limita con el Río de la Plata, es posible hallar especies nativas de la ecorregión como el "ceibo" (Erythrina crista-galli L.) o el "sauce criollo" (Salix humboldtiana Willd.), junto a especies naturalizadas desde hace cientos de años como el "ricino" (Ricinus communis L.) (Lahitte et al., 1998; Valla et al., 2001; Matteucci, 2012).
Recopilación, organización y análisis de la información

Se trabajó principalmente con información original recopilada entre septiembre de 2018 y junio de 2019. Un total de 18 personas adultas, 11 varones y 7 mujeres, de entre 22 y 69 años, proveyeron información pormenorizada sobre la temática. En todos los casos se obtuvo el consentimiento informado previo de cada entrevistado en forma oral.

Para la selección de los entrevistados se empleó un muestreo intencional no probabilístico (Albuquerque et al., 2014). Las características seleccionadas fueron: a) que vivan y/o trabajen en la zona de estudio, y b) que presenten un estrecho contacto con las plantas debido a sus ocupaciones, intereses personales y/o historias de vida. Del total de entrevistados, 14 fueron de nacionalidad argentina, 1 de nacionalidad paraguaya y 3 de origen peruano. La información se recopiló mediante entrevistas abiertas y semiestructuradas y recorridos por el entorno, incluyendo espacios públicos y domésticos, usando fotografías como material adicional durante las consultas (Arenas et Martínez, 2012). La identidad de las especies se determinó a partir de material botánico de referencia recopilado durante los recorridos por el entorno, que se conserva actualmente en la colección etnobiológica del Grupo de Etnobiología de la FCEyNUBA, lugar de trabajo de los autores, y con los que se continúan desarrollando estudios vinculados a su toxicidad y a otros aspectos de su etnobotánica. A lo largo del trabajo se sigue la clasificación propuesta por World Flora Online (2021). Adicionalmente, se realizó una revisión exhaustiva de fuentes bibliográficas, en especial de trabajos de los campos de la toxicología, la química y disciplinas afines, en relación a la toxicidad de las especies consideras tóxicas.

Los datos fueron transcriptos y organizados ad-hoc en planillas de datos y carpetas de información digitales. Los efectos tóxicos registrados se clasificaron en función de los sistemas corporales que afectan siguiendo la categorización propuesta por el ICPC-2e (WICC, 2000) (Tabla 1). 


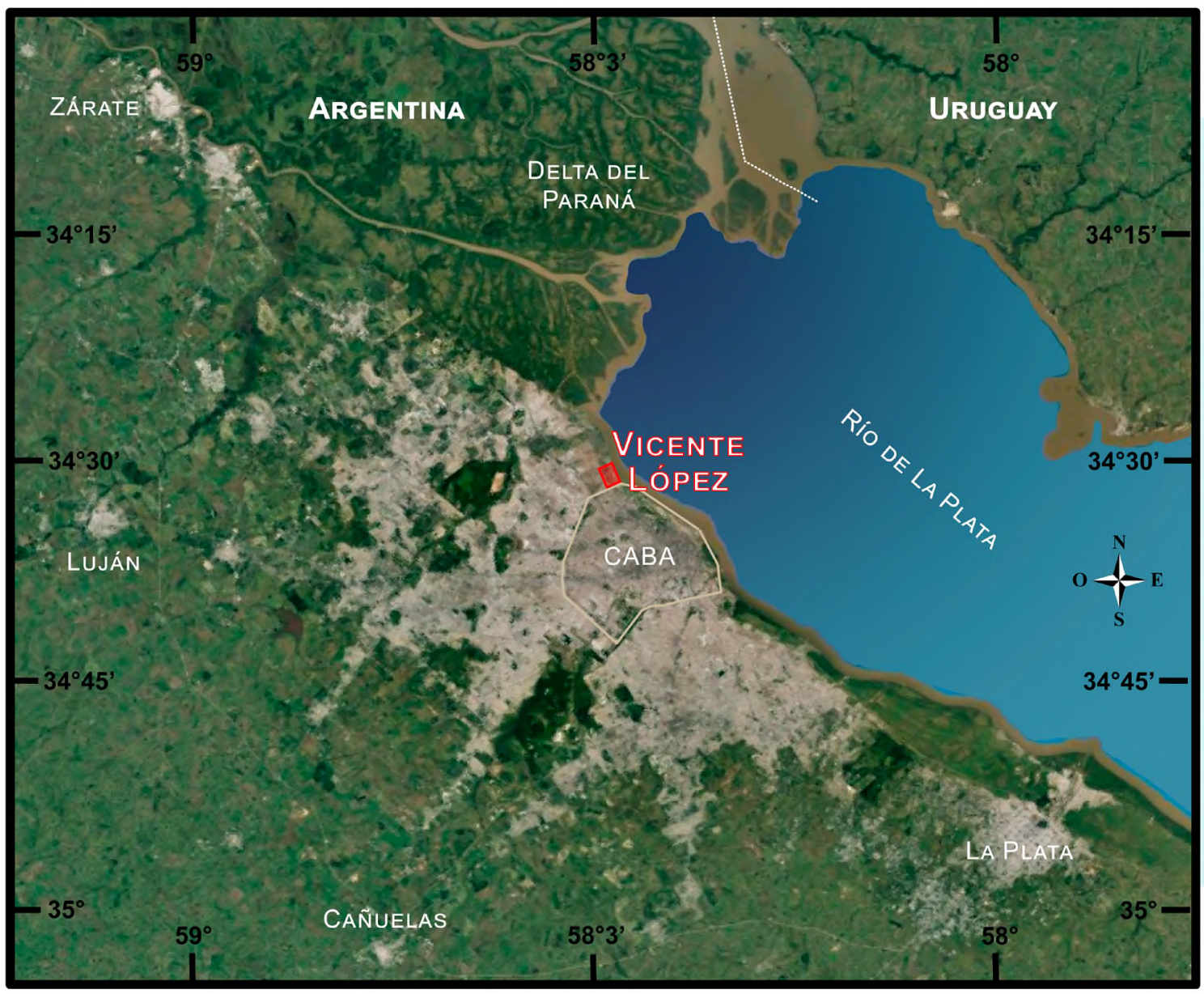

Fig. 1. Área de estudio. Zárate, Luján, Cañuelas y La Plata conforman los límites del Ảrea Metropolitana de Buenos Aires (AMBA), dentro de la que se encuentra el partido de Vicente López. CABA: Ciudad Autónoma de Buenos Aires (capital del país).

Fig. 1. Study area. Zárate, Luján, Cañuelas and La Plata delimit the Metropolitan Area of Buenos Aires (known as AMBA, its acronym in Spanish), where Vicente López's district is included. CABA: Ciudad Autónoma de Buenos Aires (capital city of the country).

Con el fin de caracterizar el CBU en relación a las plantas tóxicas se realizó un análisis holístico de la información. Como parte de este análisis, y para evaluar el grado de variabilidad en los conocimientos sobre plantas tóxicas, se calcularon dos índices de consenso (como número de entrevistados en función del total de entrevistados): a) consenso por especie $\left(\mathrm{C}_{\mathrm{sp}}\right)$, el consenso sobre si la especie es o no tóxica; y b) consenso de parte-efecto $\left(\mathrm{C}_{\mathrm{pv-e}}\right)$, el consenso sobre el efecto que cada parte vegetal produce. Los índices se expresaron en porcentaje.

\section{Resultados}

Plantas tóxicas del partido de Vicente López $\mathrm{Se}$ registraron 42 especies que son reconocidas como tóxicas por los entrevistados (Tabla 2), las cuales pertenecen a 23 familias de plantas vasculares. La familia que tuvo mayor representación fue Solanaceae, con 7 de 42 especies tóxicas (16,7\% del total), seguida por Apocynaceae y Euphorbiaceae, con 5 de 42 especies $(11,9 \%)$ y Araceae y Aristolochiaceae, con 3 de $42(7,1 \%)$. Del total de especies, 25 son 
Tabla 1. Clasificación de los efectos en función de los sistemas corporales afectados.

Table 1. Classification of the effects according to the affected body systems.

\begin{tabular}{|ll|}
\hline \multicolumn{1}{|c|}{ Sistema corporal } & \multicolumn{1}{c|}{ Efecto } \\
Cardiovascular (1) & Alteraciones cardíacas (1) \\
Dérmico (18) & $\begin{array}{l}\text { Dolor (1), erupción cutánea (dermatitis, urticante) (16), hinchazón } \\
\text { localizada (1) }\end{array}$ \\
Digestivo (8) & $\begin{array}{l}\text { Diarrea (2), distensión abdominal (2), enfermedad en hígado (1), } \\
\text { vómitos (3) }\end{array}$ \\
General e inespecífico (20) & Cáncer (3), muerte (9), tóxico (6), fiebre (2) \\
Nervioso (7) & Alucinaciones (1), dolor de cabeza (1), psicotrópico (4), mareos (1) \\
Ocular (8) & Ceguera temporal (2), irritación en ojos (3), lesión en ojos (3) \\
Respiratorio (5) & Dificultad para respirar (1), irritación de las mucosas (2), rinitis alérgica \\
\hline
\end{tabular}

Referencias: Los números entre paréntesis indican la cantidad de especies que afectan a cada sistema corporal o que producen cada tipo de efecto.

exóticas de la región rioplatense $(59,5 \%)$ y 17 son nativas $(40,5 \%)$.

Las especies que presentaron mayor $\mathrm{C}_{\mathrm{sp}}$ fueron el "floripondio" [Brugmansia arborea (L.) Sweet/Brugmansia suaveolens (Willd.) Sweet] $(50 \%, 9$ de 18 entrevistados), el "paraíso" y el "laurel de jardín" $(38,9 \%, 7 / 18)$, el "ricino" $(33,3 \%, 6 / 18)$, y el "duraznillo negro" (Cestrum parqui L'Hér.), la "cicuta" (Conium maculatum L.) y la "difenbaquia" [Dieffenbachia seguine (Jacq.) Schott] (27,8\%, 5/18) (Fig. 2). De estas 7 especies, 5 pertenecen a alguna de las familias más representativas y 6 de ellas son exóticas.

Se documentaron 18 efectos (síntomas y signos) que afectan a 6 sistemas corporales (Tabla 1) y 4 efectos $\sin$ especificidad definida, los cuales se han agrupado bajo la categoría "general e inespecífico", con 20 de 42 especies capaces de ocasionarlos. De los sistemas específicos, el que según las personas consultadas se ve mayormente afectado es el dérmico (18/42 especies), seguido por el ocular y el digestivo ( $8 / 42$ especies cada uno), el nervioso (7/42) y el respiratorio $(5 / 42)$. El sistema cardiovascular se ve comprometido únicamente por una de las especies reportadas (Tabla 1). Al respecto, se observa que muchas de las especies consignadas pueden afectar a más de un sistema corporal, ya sea por vía de distintos mecanismos de acción asociados a una misma o a distintas partes vegetales, o bien por tratarse de efectos de carácter sistémico (Tabla 2). Con respecto a la severidad, los efectos registrados varían desde leves, como suelen ser las erupciones cutáneas, la distención abdominal o el dolor de cabeza, hasta graves como la ceguera temporal, las alteraciones cardíacas, el cáncer y la muerte. En relación a este último efecto se observa que siempre es ocasionado por el mecanismo de ingesta, y que cinco de las especies con mayor $\mathrm{C}_{\mathrm{sp}}$ son capaces de ocasionarlo (Tabla 2).

El mayor valor de $\mathrm{C}_{\mathrm{pr}-\mathrm{e}}$ fue de $38,9 \%$ (7 de 18 entrevistados), correspondiente al efecto psicotrópico consecuencia de la ingestión de las flores del "floripondio", que desde la perspectiva emic es considerado un efecto tóxico. A su vez, la ingestión de esta parte de la planta es capaz de ocasionar la muerte acorde con el $22,2 \%$ de los entrevistados (4/18). De igual forma, con un valor de $\mathrm{C}_{\mathrm{pv}-\mathrm{e}}$ del $22,2 \%$ (4/18), el consumo de las hojas o del tallo de la "cicuta" presenta un efecto letal. Por último, con el mismo valor de consenso, se destacaron otras especies capaces de ocasionar efectos de menor severidad, como el "ombú" (Phytolacca dioica L.), cuyas hojas al ser ingeridas pueden originar diarrea, $u$ otras que producen erupciones cutáneas por contacto, 
Tabla 2. Plantas tóxicas reportadas, consensos y bibliografía que cita el mismo efecto/parte/mecanismo.

Table 2. Toxic plants reported, consensus and bibliography that cite the same effect/part/mechanism.

\begin{tabular}{|c|c|c|c|c|c|c|c|c|c|}
\hline Familia & Especie (voucher) & Condic. & $\begin{array}{l}\text { Nombre } \\
\text { local }\end{array}$ & Parte tóxica & Mecanismo & Efecto & $\mathrm{C}_{\mathrm{sp}}$ & $C_{p v-e}$ & Bibliografía \\
\hline Anacardiaceae & $\begin{array}{c}\text { Toxicodendron } \\
\text { succedaneum (L.) Kuntze } \\
\text { (FV 54) }\end{array}$ & Exótica & Rhus & $\begin{array}{c}\text { Fluido interno } \\
\text { Hoja }\end{array}$ & $\begin{array}{l}\text { Contacto } \\
\text { Contacto }\end{array}$ & $\begin{array}{l}\text { Lesión en ojos } \\
\text { Erupción cutánea }\end{array}$ & 11,1 & $\begin{array}{l}5,6 \\
5,6\end{array}$ & $\begin{array}{c}\text { Peate (2007) } \\
\text { Slaughter et al. } \\
(2017)\end{array}$ \\
\hline Apiaceae & $\begin{array}{c}\text { Conium maculatum L. } \\
\text { (FV 58) }\end{array}$ & Exótica & Cicuta & Hoja y tallo & Ingestión & Muerte & 27,8 & 22,2 & Filmer (2012) \\
\hline \multirow[t]{8}{*}{ Apocynaceae } & $\begin{array}{c}\text { Araujia sericifera Brot. } \\
\text { (FV 38) }\end{array}$ & Nativa & Tasi & Hoja y tallo & Ingestión & Sin especificar & 11,1 & 5,6 & $\begin{array}{l}\text { Winks et Fowler } \\
(2000)\end{array}$ \\
\hline & $\begin{array}{c}\text { Asclepias curassavica L. } \\
\text { (FV 30) }\end{array}$ & Exótica & $\begin{array}{l}\text { Bandera } \\
\text { española }\end{array}$ & $\begin{array}{c}\text { Fluido interno } \\
\text { Hoja y tallo }\end{array}$ & $\begin{array}{l}\text { Contacto } \\
\text { Ingestión }\end{array}$ & $\begin{array}{l}\text { Lesión en ojos } \\
\text { Sin especificar }\end{array}$ & 11,1 & $\begin{array}{l}5,6 \\
5,6\end{array}$ & $\begin{array}{c}\text { Gaig et al. (2005) } \\
\text { Alonso et } \\
\text { Desmarchelier (2015) }\end{array}$ \\
\hline & & & & Fluido interno & Contacto & Erupción cutánea & & 5,6 & $\begin{array}{c}\text { Alonso et } \\
\text { Desmarchelier (2015); } \\
\text { Chakraborty (1995) }\end{array}$ \\
\hline & Asclepias mellodora A. St.- & Nativa & Yerba de la & Hoja y tallo & Ingestión & Sin especificar & 11,1 & 5,6 & García et al. (2017) \\
\hline & Hil. (FV 59) & & víbora & Fluido interno & Contacto & Erupción cutánea & & 5,6 & Chakraborty (1995) \\
\hline & $\begin{array}{l}\text { Nerium oleander L. } \\
\text { (FV 15, FV 50) }\end{array}$ & Exótica & $\begin{array}{l}\text { Laurel de } \\
\text { jardín, laurel }\end{array}$ & $\begin{array}{l}\text { Fluido interno } \\
\text { Hoja y tallo }\end{array}$ & $\begin{array}{l}\text { Contacto } \\
\text { Ingestión }\end{array}$ & $\begin{array}{l}\text { Erupción cutánea } \\
\text { Sin especificar }\end{array}$ & 38,9 & $\begin{array}{l}22,2 \\
5,6\end{array}$ & \\
\hline & & & $\begin{array}{l}\text { de flor, laurel } \\
\text { rosa }\end{array}$ & & & $\begin{array}{l}\text { Tóxico para otros } \\
\text { mamíferos (c) }\end{array}$ & & 5,6 & $\begin{array}{l}\text { Filmer (2012); } \\
\text { Severino (2009) }\end{array}$ \\
\hline & & & & & $\begin{array}{l}\text { Inhalación } \\
\text { (b) }\end{array}$ & $\begin{array}{l}\text { Irritación en ojos } \\
\text { y mucosas }\end{array}$ & & 5,6 & $\begin{array}{c}\text { Senthilkumaran et al. } \\
\text { (2011) }\end{array}$ \\
\hline \multirow[t]{6}{*}{ Araceae } & $\begin{array}{l}\text { Oxypetalum solanoides } \\
\text { Hook. \& Arn. (FV 60) }\end{array}$ & Nativa & $\begin{array}{l}\text { Plumerillo } \\
\text { negro }\end{array}$ & Hoja y tallo & Ingestión & Sin especificar & 5,6 & 5,6 & Freire et al. (2005) \\
\hline & $\begin{array}{l}\text { Alocasia macrorrhizos (L.) } \\
\text { G. Don / A. odora (Lindl.) } \\
\text { K. Koch (FV 61) (a) }\end{array}$ & Exótica & $\begin{array}{l}\text { Oreja de } \\
\text { elefante }\end{array}$ & Fluido interno & Contacto & Erupción cutánea & 16,7 & 16,7 & Filmer (2012) \\
\hline & $\begin{array}{l}\text { Dieffenbachia seguine } \\
\text { (Jacq.) Schott (FV 62) }\end{array}$ & Exótica & $\begin{array}{l}\text { Difenbaquia, } \\
\text { mariana }\end{array}$ & Fluido interno & Contacto & Erupción cutánea & 27,8 & 22,2 & \multirow[t]{2}{*}{$\begin{array}{l}\text { Filmer (2012); Modi } \\
\text { et al. (2009); Unlu et } \\
\text { Kocabaş (2020) }\end{array}$} \\
\hline & & & & & & $\begin{array}{l}\text { Dificultad para } \\
\text { respirar }\end{array}$ & & 5,6 & \\
\hline & & & & & Ingestión & Vómitos & & 5,6 & $\begin{array}{l}\text { Unlu et Kocabaş } \\
(2020)\end{array}$ \\
\hline & $\begin{array}{c}\text { Monstera deliciosa Liebm. } \\
(\mathrm{FV} 63)\end{array}$ & Exótica & $\begin{array}{l}\text { Costilla de } \\
\text { Adán }\end{array}$ & Fluido interno & Contacto & Erupción cutánea & 5,6 & 5,6 & Filmer (2012) \\
\hline
\end{tabular}




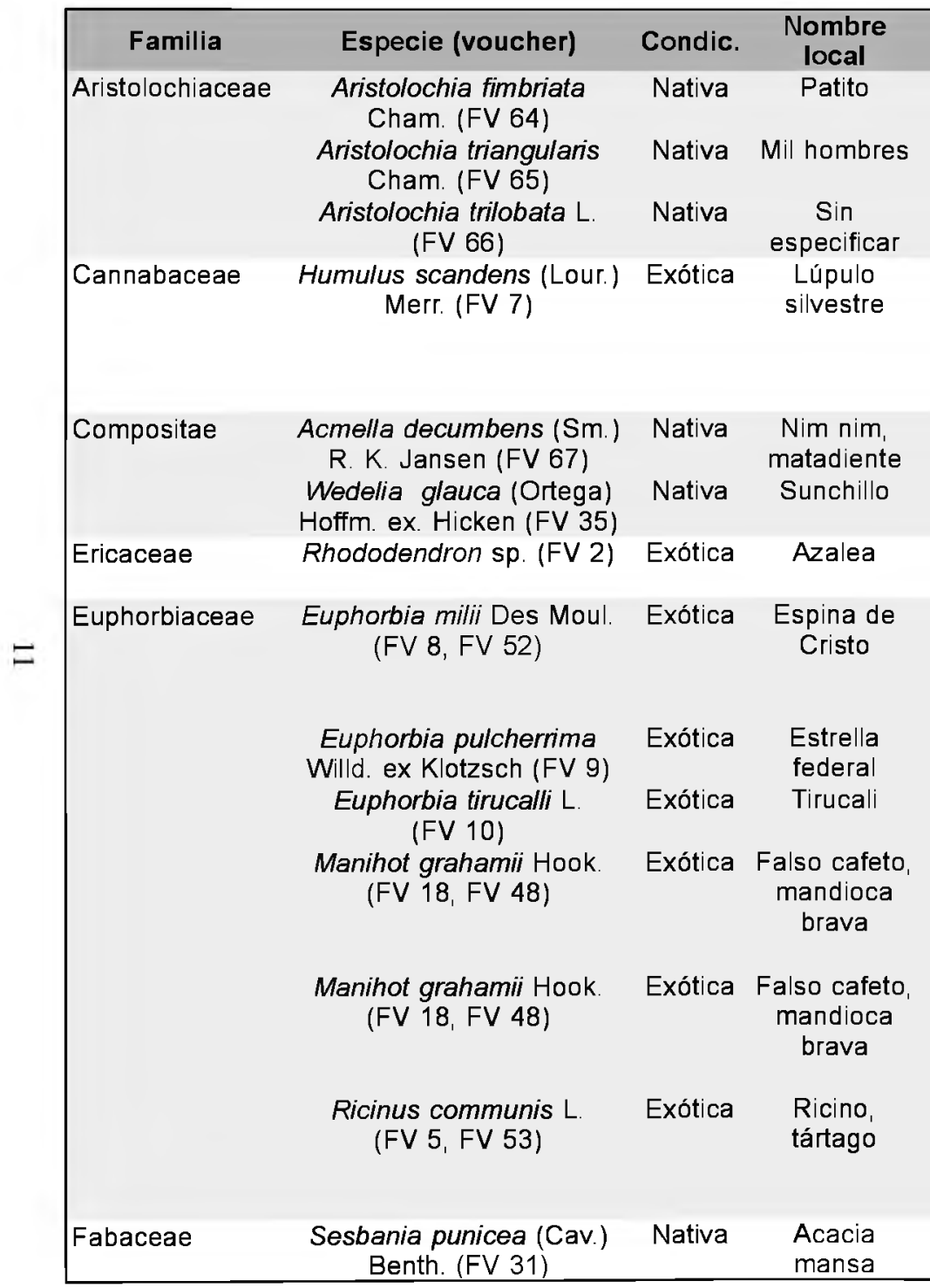




\section{Parte tóxica Mecanismo}

Efecto

$C_{\text {sp }} \quad C_{\text {pv-e }}$

Bibliografía

Hoja Ingestión

Cáncer

$5,6 \quad 5,6 \quad$ Schmeiser et al.

(2008)

Hoja Ingestión Cáncer $\quad 5,6 \quad 5,6 \quad$ Schmelser et al.

(2008)

Hoja Ingestión Cáncer $5,6 \quad 5,6 \quad$ Schmelser et al.

(2008)

Hoja Contacto Erupción cutánea $11,1 \quad 11,1$

Filmer (2012)

Flor Inhalación Psicotrópico $5,6 \quad 5,6$

(b)

(Humulus lupulus)

Zanoli et Zavatti (2008) (Humulus lupulus)

Tallo Ingestión Muerte $\quad 5,6 \quad 5,6$

Hoja y tallo Ingestión Tóxico para otros $5,6 \quad 5,6$ Rivero et al. (2010) mamíferos (c)

Hoja Ingestión Tóxico para otros mamíferos (c)

Fluido interno Contacto

Erupción cutánea, lesión en ojos y ceguera temporal

Fluido interno Contacto Erupción cutánea 16,7 16,7 Filmer (2012); Modi et

Fluido interno Contacto Ceguera temporal 5,6 5,6 Filmer (2012)

Semilla Ingestión Sin especificar 22,2 11,1 Freire et al. (2005): Valla et al. (2001)

Fluido interno Contacto Erupción cutánea 5,6 Santos et al. (2011) (Manihot esculenta)

Madera Inhalación Irritación en ojos 22,2 11,1

(b)

y mucosas, y dolor de cabeza

Fruto Ingestión Sin especificar

Semilla

Ingestión

Muerte

33,3 16,7 Worbs et al. (2011) 11,1 Fllmer (2012); Worbs et al. (2011)

Fluido interno Contacto Erupción cutánea 5,6 Modi et al. (2009) Semilla Ingestión

$5,6 \quad 5,6 \quad$ Terblache et al. 


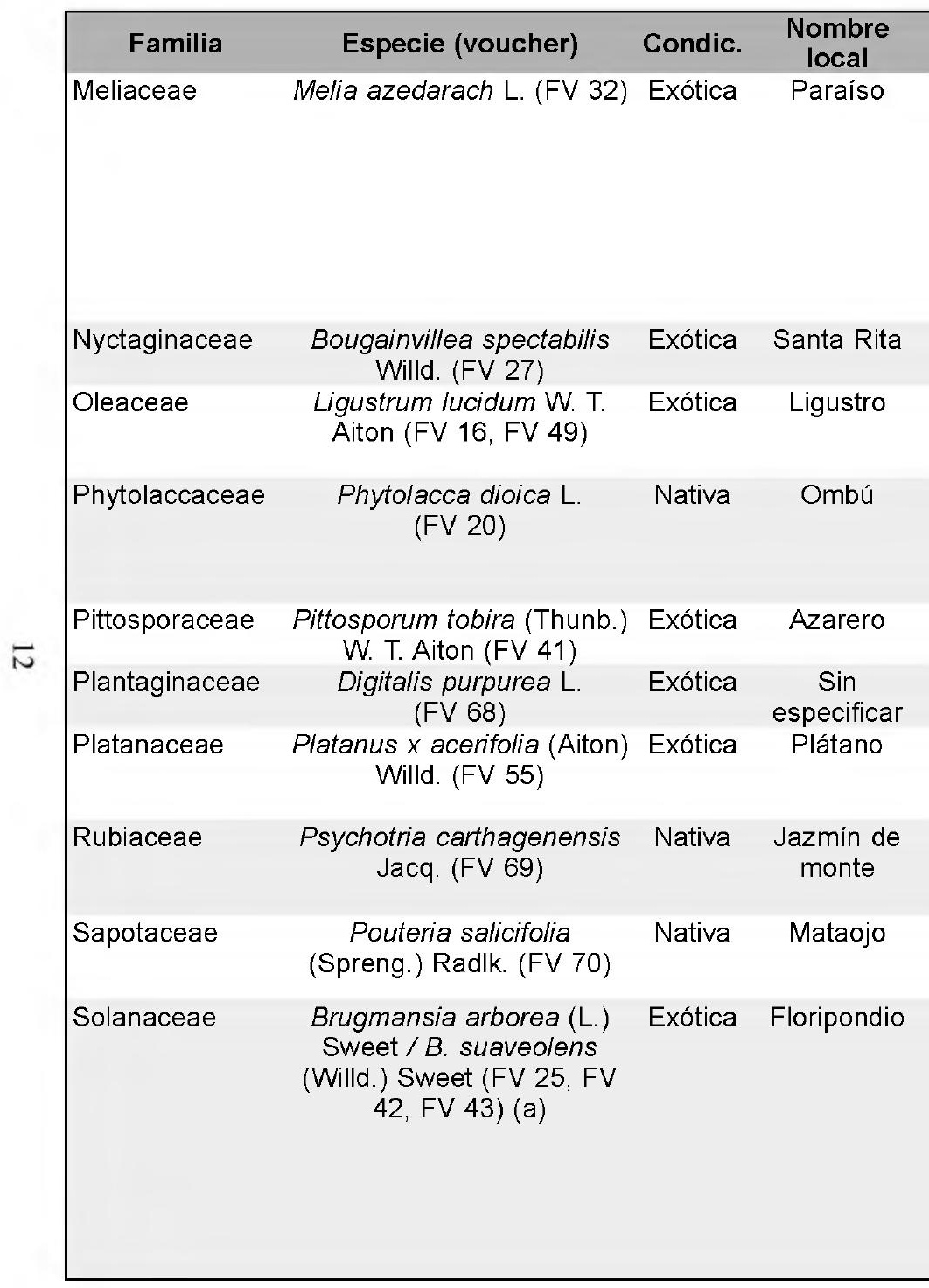




\section{Parte tóxica Mecanismo \\ Efecto \\ $\mathrm{C}_{\mathrm{sp}} \quad \mathrm{C}_{\mathrm{pv}-\mathrm{e}}$ \\ Bibliografía}

Fruto Ingestión

Sin especificar

38,9 16,7 Filmer (2012); Worbs

Tóxico para otros

et al. (2011)

mamíferos (c)

Hoja y tallo Ingestión

Muerte

11,1 Phua et al. (2008); Filmer (2012)

5,6 Phua et al. (2008);

Filmer (2012)

Madera Inhalación Sin especificar $\quad 5,6$

(b)

Espina Contacto Hinchazón $5,6 \quad 5,6 \quad$ Filmer (2012); Worbs localizada y dolor et al. (2011)

Polen Inhalación Rinitis alérgica $5,6 \quad 5,6 \quad$ Cariñanos et (de polen) Casares-Porcel (2011)

Hoja Ingestión Diarrea 22,2 22,2 Lord et Hartley (2010) Enfermedad en $\quad 11,1$ Ashafa et al. (2010) hígado

Fluido interno Contacto Mareos y fiebre 5,6 5,6

Sin especificar Ingestión Alteraciones $5,6 \quad 5,6 \quad$ Filmer (2012) cardiacas

Fruto Inhalación Rinitis alérgica $16,7 \quad 16,7$ (de vilano)

Hoja Ingestión Psicotrópico $5,6 \quad 5,6$

Cariñanos et Casares-Porcel (2011)

Madera Inhalación Irritación en ojos 5,6 5,6 Mandrile et Cafferata (b)
Flor
Ingestión
Psicotrópico
$50 \quad 38,9$
Inhalación Psicotrópico
Muerte
(b)
Hoja Ingestión Psicotrópico y muerte
Doan et al. (2019); Filmer (2012); Isbister et al. (2003) 22,2 Jayawickreme et al. (2019) 5,6 Isbister et al. (2003) 5,6 Doan et al. (2019); Filmer (2012)

(1993) 


\begin{tabular}{|c|c|c|c|c|c|c|c|c|c|}
\hline Familia & Especie (voucher) & Condic. & $\begin{array}{l}\text { Nombre } \\
\text { local }\end{array}$ & Parte tóxica & Mecanismo & Efecto & $\mathrm{C}_{\mathrm{sp}}$ & $C_{p v-e}$ & Bibliografía \\
\hline \multirow[t]{8}{*}{ Solanaceae } & $\begin{array}{l}\text { Brunfelsia australis Benth. } \\
\qquad(\mathrm{FV} 23)\end{array}$ & Exótica & $\begin{array}{l}\text { Jazmín } \\
\text { paraguayo }\end{array}$ & Hoja & Ingestión & $\begin{array}{l}\text { Distensión } \\
\text { abdominal y } \\
\text { muerte en otros } \\
\text { mamíferos }\end{array}$ & 5,6 & 5,6 & $\begin{array}{l}\text { Zeinsteger et al. } \\
\qquad(2016)\end{array}$ \\
\hline & $\begin{array}{c}\text { Cestrum euanthes Schltdl. } \\
\text { (FV 46) }\end{array}$ & Nativa & $\begin{array}{l}\text { Duraznillo } \\
\text { negro, } \\
\text { hediondillo }\end{array}$ & $\begin{array}{l}\text { Hoja, tallo y } \\
\text { fruto }\end{array}$ & Ingestión & Sin especificar & 11,1 & 11,1 & Barberón et al. (2020) \\
\hline & \multirow[t]{2}{*}{$\begin{array}{l}\text { Cestrum parqui L'Hér. } \\
\quad(\mathrm{FV} 44,45,47)\end{array}$} & \multirow[t]{2}{*}{ Nativa } & \multirow{2}{*}{$\begin{array}{l}\text { Duraznillo } \\
\text { negro, } \\
\text { hediondillo }\end{array}$} & \multirow[t]{2}{*}{$\begin{array}{l}\text { Hoja, tallo y } \\
\text { fruto }\end{array}$} & \multirow[t]{2}{*}{ Ingestión } & Sin especificar & \multirow[t]{2}{*}{27,8} & 16,7 & Barberón et al. (2020) \\
\hline & & & & & & $\begin{array}{c}\text { Distensión } \\
\text { abdominal y } \\
\text { muerte en otros } \\
\text { mamíferos (c) }\end{array}$ & & 11,1 & Barberón et al. (2020) \\
\hline & $\begin{array}{c}\text { Nicotiana glauca Graham } \\
\text { (FV 4, FV 39) }\end{array}$ & Exótica & Palán Palán & Hoja y tallo & Ingestión & $\begin{array}{l}\text { Tóxico para otros } \\
\text { mamíferos (c) }\end{array}$ & 5,6 & 5,6 & $\begin{array}{c}\text { Alonso et } \\
\text { Desmarchelier (2015); } \\
\text { Filmer (2012) }\end{array}$ \\
\hline & $\begin{array}{l}\text { Salpichroa origanifolia } \\
\text { (Lam.) Baill. (FV 26) }\end{array}$ & Nativa & $\begin{array}{l}\text { Huevito de } \\
\text { gallo }\end{array}$ & Hoja & Ingestión & Psicotrópico & 5,6 & 5,6 & Lahitte et al. (1998) \\
\hline & \multirow[t]{2}{*}{$\begin{array}{c}\text { Solanum sisymbriifolium } \\
\text { Lam. (FV 29) }\end{array}$} & \multirow[t]{2}{*}{ Nativa } & \multirow{2}{*}{$\begin{array}{l}\text { Revienta } \\
\text { caballo, } \\
\text { espina } \\
\text { colorada, } \\
\text { tutiá }\end{array}$} & Hoja & Ingestión & Vómitos y diarrea & \multirow[t]{2}{*}{16,7} & 5,6 & \multirow{2}{*}{$\begin{array}{c}\text { Alonso et } \\
\text { Desmarchelier (2015) } \\
\text { Alonso et } \\
\text { Desmarchelier (2015) }\end{array}$} \\
\hline & & & & Fruto & Ingestión & $\begin{array}{l}\text { Tóxico para otros } \\
\text { mamíferos (c) }\end{array}$ & & 5,6 & \\
\hline Taxaceae & Taxus baccata L. (FV 71) & Exótica & Tejo & Fluido interno & Contacto & Erupción cutánea & 5,6 & 5,6 & Wilson et al. (2001) \\
\hline Urticaeae & $\begin{array}{l}\text { Urtica dioica L. I U. urens } \\
\text { L. (FV 56, FV 57) (a) }\end{array}$ & Exótica & Ortiga & Hoja y tallo & Contacto & Erupción cutánea & 22,2 & 22,2 & Filmer (2012) \\
\hline \multirow[t]{2}{*}{ Verbenaceae } & \multirow[t]{2}{*}{ Lantana camara L. (FV 33) } & \multirow[t]{2}{*}{ Nativa } & \multirow[t]{2}{*}{ Lantana } & Fruto & Ingestión & $\begin{array}{l}\text { Fiebre } \\
\text { Vómitos }\end{array}$ & 16,7 & $\begin{array}{c}11,1 \\
5,6\end{array}$ & \multirow{2}{*}{$\begin{array}{c}\text { Alonso et } \\
\text { Desmarchelier (2015) } \\
\text { Alonso et } \\
\text { Desmarchelier (2015) }\end{array}$} \\
\hline & & & & Hoja & Contacto & Erupción cutánea & & 5,6 & \\
\hline
\end{tabular}

Referencias: Voucher: FV= Federico Valerio. Condic.: condición en la región rioplatense. Nombres locales: se indica en negrita el nombre más usual. Mecanismos: mecanismos de toxicidad. $\mathrm{C}_{\mathrm{sp}}$ : consenso por especie (en \%). $\mathrm{C}_{\mathrm{pvc}}$ : consenso por especie-parte tóxica-efecto (en \%). Bibliografia: se indican entre paréntesis cuando se encontró la misma información para otra especie emparentada. (a): pares de especies que corresponden a una misma etnoespecie. (b): casos en los que el efecto se produce por inhalación de humo proveniente de la combustión de las partes vegetales correspondientes. (c) el término otros mamíferos alude tanto a animales hogareños como a ganado. 

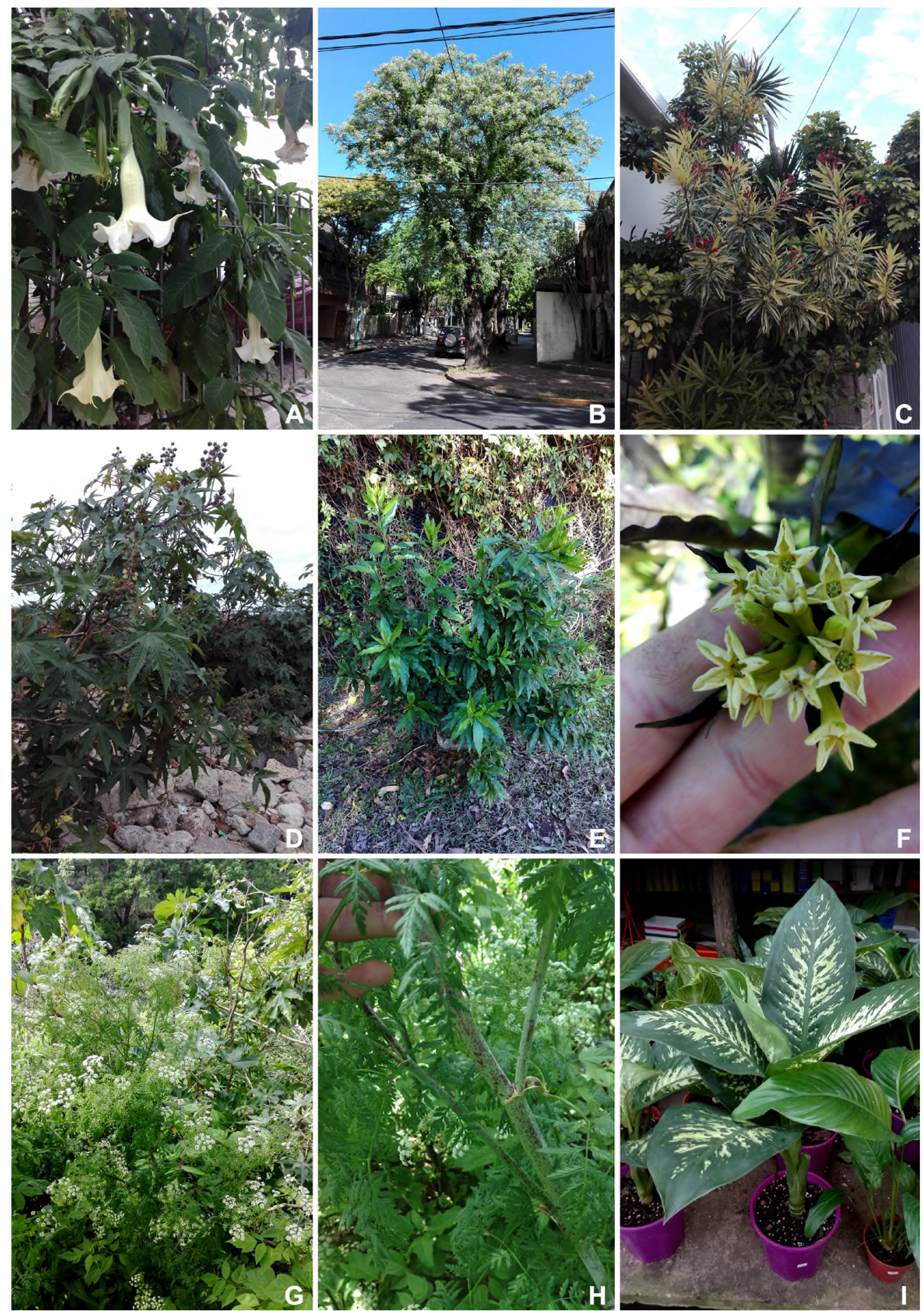

Fig. 2. Plantas con mayor consenso por especie $\left(\mathrm{C}_{\mathrm{q}}\right)$. A: Floripondio (Brugmansia arborea). B: Paraíso (Melia azedarach). C: Laurel de jardín (Nerium oleander). D: Ricino (Ricinus communis). E y F: Duraznillo negro (Cestrum parqui). G y H: Cicuta (Conium maculatum). I: Difenbaquia (Dieffenbachia seguine).

Fig. 2. Plants with the highest consensus by species $\left(\mathrm{C}_{\mathrm{p}}\right)$. A: Floripondio (Brugmansia arborea). B: Paraíso (Melia azedarach). C: Laurel de jardín (Nerium oleander). D: Ricino (Ricinus communis). E y F: Duraznillo negro (Cestrum parqui). G y H: Cicuta (Conium maculatum). I: Difenbaquia (Dieffenbachia seguine). 
como la "difenbaquia" y el "laurel de jardín". A excepción del "ombú" $\left(\mathrm{C}_{\mathrm{sp}}=22,2 \%, 4 / 18\right)$, todas estas especies también presentan los mayores valores de $\mathrm{C}_{\mathrm{sp}}$.

Concepto vernáculo sobre las plantas tóxicas

Los entrevistados coincidieron en que una planta tóxica es aquella que produce una alteración en el organismo, la cual han vinculado principalmente con un daño (i.e. efecto negativo). Sin embargo, a medida que se avanzó con las entrevistas se hizo evidente que no todas las plantas que se consideran capaces de ocasionar un daño son concebidas como tóxicas. En esta línea, y en base a la información registrada a campo, se analizaron los factores que entran en juego a la hora de distinguir entre plantas propiamente tóxicas y plantas dañinas, pero sin toxicidad asociada. A partir de ello, se dilucidaron los criterios subyacentes en la clasificación de las plantas como tóxicas. Estos son: a) Compuestos químicos como agente causal del efecto nocivo; b) Cantidad de material vegetal necesario para que ocurra el efecto nocivo; c) Cantidad de personas que logra afectar; d) Severidad del efecto nocivo; e) Probabilidad de ejercer el efecto nocivo; f) Utilidad de la planta. A continuación se explica y describe cada uno:

\section{a) Compuestos quimicos como agente causal del} efecto nocivo. Se observó que para algunas personas el efecto nocivo es consecuencia de la acción de compuestos químicos. De esta forma, este criterio excluye de la condición de tóxica a todas las plantas que producen únicamente un daño mecánico, como aquellos ocasionados por espinas, aguijones $\mathrm{u}$ otras estructuras punzantes. Un ejemplo mencionado es el ocasionado por las espinas del "ñapinday" [Senegalia bonariensis (Gillies ex Hook. \& Arn.) Seigler \& Ebinger], cuyo efecto sobre la piel (dolor e inflamación) es atribuido a una lesión mecánica y la consecuente infección de la herida. Esta condición no está restringida sólo a las plantas que presentan estructuras punzantes, ya que también se ha hecho referencia a que los frutos del "plátano" producen un daño mecánico en las mucosas, motivo por el cual no se la considera una planta tóxica. b) Cantidad de material vegetal necesario para que ocurra el efecto nocivo. En este caso, son tóxicas únicamente las plantas que en cantidades pequeñas son capaces de producir el efecto nocivo. Un buen ejemplo para comprender mejor este criterio es el que brindó uno de los entrevistados, quien explicó: "si te pica una abeja no pasa nada, pero si te pican 100 abejas te podés morir y no por eso las abejas son tóxicas". En relación a este concepto, se han citado varios casos de plantas comestibles que podrían generar inconvenientes en caso de que se consuman en forma excesiva. Tal es el caso de la "espinaca" (Spinacia oleracea L.) o la "remolacha" (Beta vulgaris L.), las cuales pueden desencadenar trastornos digestivos o adormecimiento y paralización del aparato bucal en caso de consumirse los jugos concentrados de las hojas o la raíz, respectivamente. De igual forma, otras especies que podrían generar problemas en caso de consumirse en exceso son el "vinagrillo" (Oxalis articulata Savigny), la "albahaca" (Ocimum basilicum L.) y el "laurel comestible" (Laurus nobilis L.), siendo capaces de provocar la formación de piedras en los riñones, cáncer o muerte, respectivamente, aun cuando ninguna de ellas es clasificada como tóxica.

c) Cantidad de personas que logra afectar. Con este criterio se considera que solo son tóxicas las especies vegetales capaces de ocasionar efectos adversos en todas o en la mayoría de las personas, diferenciándolas de aquellas que solo afectan a individuos que poseen una sensibilidad o predisposición particular.

De acuerdo a la información aportada por las personas consultadas, algunos ejemplos se corresponden con especies que ocasionan erupciones cutáneas, como las del género Ficus (Ficus benjamina L., Ficus carica L., Ficus elastica Roxb. ex Hornem., Ficus pumila L.), el "juníperus" [Juniperus procumbens (Siebold ex Endl.) Siebold ex Miq.] y la "lipia" [Lippia alba (Mill.) N. E. Br. ex Britton \& P. Wilson], o a aquellas que ocasionan rinitis alérgica como el "plátano" o el "tilo" [Tilia viridis (Bayer) L. Simonkai 
subsp. $\times$ moltkei]. Otro caso mencionado es la "palta" (Persea americana Mill.), cuyo fruto es capaz de producir hinchazón en la boca de personas alérgicas.

Si bien los ejemplos citados anteriormente dan cuenta de efectos leves, también se han registrado casos de plantas como el "horco quebracho" (Schinopsis marginata Engl.) o el "molle de beber" [Lithraea molleoides (Vell.) Engl.], que son capaces de ocasionar reacciones alérgicas de mayor severidad, que desembocan en la hinchazón de las manos y el cierre de las vías respiratorias cuando las personas con predisposición entran en contacto con los fluidos internos. Por su parte, el "suico" (Tagetes minuta L.) ha sido destacado como una planta medicinal, pero contraindicada en mujeres embarazadas o lactantes, en quienes puede producir un efecto tóxico.

\section{d) Severidad del efecto nocivo. Con este criterio} se clasifica como tóxicas únicamente a las plantas que producen efectos graves sobre la salud. Los entrevistados describen estos efectos como aquellos capaces de poner en riesgo la salud, ocasionando la muerte o provocando alguna clase de daño que requiera de intervención médica o de algún tipo de tratamiento, como medicación de efecto sistémico o local. Por contraposición, los efectos leves son entendidos como aquellos que generan una baja intensidad de molestia o dolor, con acción localizada y de corta permanencia en el organismo.

Los efectos leves han sido relacionados mayormente con las erupciones cutáneas, como las que pueden ser ocasionadas cuando se entra en contacto con los fluidos internos del "agapanto"; con las hojas de la "lantana" (Lantana camara L.), de la "menta" (Mentha sp.), de la "prímula" (Primula obconica Hance) o de la "verbena" (Verbena sp.); o con el tallo y pecíolos del "helecho arborescente" (Alsophila sp.). Las especies previamente mencionadas no son consideradas tóxicas; sin embargo, es importante aclarar que en varios casos la severidad del efecto nocivo que produce una especie es percibida de manera diferente por los entrevistados. Así, algunas de las personas que utilizaron este criterio consideran tóxicas a especies que producen erupciones cutáneas, como la "oreja de elefante" [Alocasia macrorrhizos (L.) G. Don y A. odora (Lindl.) K. Koch] o la "ortiga" (Urtica sp.), o afecciones respiratorias, como el "plátano" (Tabla 2), ya que perciben que el efecto producido es grave por ser generalizado sobre el organismo, muy doloroso o persistente, respectivamente; otras de las que usan este criterio, por el contrario, consideran que se trata de efectos leves y por ende no las clasifican como tóxicas.

e) Probabilidad de ejercer el efecto nocivo. Algunas personas consideran que son tóxicas solamente las plantas que presentan altas probabilidades de ejercer el efecto nocivo. Se registraron dos posibilidades por las cuales una planta puede no presentar dicha característica: (1) que el tóxico de la especie no sea accesible a los seres humanos u otros animales; (2) que el tóxico sí esté accesible, pero que la probabilidad de que provoque un daño sea baja.

En el primer caso puede ocurrir que la parte tóxica se encuentre debajo de la superficie del suelo ( $\mathrm{p}$. ej. órganos subterráneos), o que se encuentre en el vástago, pero que no sea capaz de ejercer el efecto dañino por ningún mecanismo (ingestión, contacto o inhalación) a menos que antes se lo procese de alguna manera. Un ejemplo es el registrado para el "timbó" [Enterolobium contortisiliquum (Vell.) Morong], que en caso de inhalarse el aserrín proveniente de la madera puede ocasionar problemas pulmonares. Por el contrario, el segundo caso refiere a especies que actúan por ingestión, pero cuya probabilidad de ejercer el efecto nocivo es baja, ya que se trata de plantas que son cultivadas domésticamente con fines ornamentales y que además carecen de atributos que las vuelven atractivas para el consumo. Algunos ejemplos mencionados fueron la "azalea" (Rhododendron sp.), el "algodonillo" (Gomphocarpus physocarpus E. Mey.), el "floripondio" y el "paraíso". Por contraposición, también se ha señalado que podrían considerarse tóxicas a todas las especies medicinales que presentan acción 
terapéutica en cantidades muy pequeñas, debido a las grandes posibilidades que hay de excederse con la dosis e intoxicarse, como por ejemplo, la "dedalera" (Digitalis purpurea L.) (Tabla 2).

f) Utilidad de la planta. En este caso se clasifica como tóxicas únicamente a aquellas especies vegetales que producen efectos negativos sobre la salud y que no presentan una utilidad medicinal o alimenticia. Así, especies como la "ortiga", que es urticante cuando se tocan las hojas o el tallo, el "aloe" (Aloe arborescens Mill.), cuyo látex puede ocasionar irritación en la piel o en las mucosas en caso de ser ingerido, la "lipia", que puede ser abortiva si se ingieren las hojas, o la "marihuana" (Cannabis sativa $\mathrm{L}$.), que tiene efecto psicotrópico al inhalarse el humo que se genera tras la combustión de las flores, no son consideradas tóxicas, ya que también presentan propiedades beneficiosas que las convierten en buenas candidatas medicinales para tratar distintas dolencias. De igual forma la "oreja de elefante", que registró uso alimenticio, no es considerada tóxica según este criterio.

\section{Representatividad de cada criterio}

En el diagrama siguiente (Fig. 3) es posible observar los distintos criterios utilizados por cada entrevistado. Se observa que los criterios "c" (cantidad de personas que logra afectar) y "f" (utilidad de la planta) son los más empleados al momento de definir si una planta es tóxica, con 9 y 7 personas, respectivamente, seguidos por el "a" (compuestos químicos como agente causal del efecto nocivo), con 6 personas, el "d" (severidad del efecto), con 5 personas, y, por último, el "b" (cantidad de material vegetal necesario para que ocurra el efecto nocivo) y el "e" (probabilidad de ejercer el efecto nocivo), con 4. Al mismo tiempo, se observa que tanto la cantidad como el tipo de criterio utilizado a la hora de distinguir entre plantas tóxicas y dañinas varían entre individuos. Así, algunos utilizan un solo criterio, como por ejemplo los entrevistados 1,3 y 9 que consideran los criterios "d", "f y "a", respectivamente, mientras que otros consideran varios, como es el caso de los entrevistados 7 (criterios: "a", "c", "d" y "f") y 15 (criterios: "a", "c", "d", "e", "f").

Actitudes de los pobladores con respecto a las plantas tóxicas

Los entrevistados presentaron diferentes actitudes con respecto a las plantas consideradas tóxicas. La primera actitud registrada fue la de aquellas personas que optan por no cultivarlas en sus hogares. Algunos relatos compilados a campo dan cuenta de esta actitud: una entrevistada comentó que rechazó un "floripondio" que le quiso obsequiar un conocido, debido a que escuchó en la televisión que se trataba de una planta peligrosa. Otro entrevistado, que trabaja en la Reserva Ecológica de Vicente López, compartió que cuando les avisan a los visitantes sobre la toxicidad de algunos de los plantines que regalan (p. ej. "duraznillo negro"), muchas personas deciden no llevarlos. Una tercera entrevistada relató su experiencia con la "difenbaquia": explicó que en inicio poseía esta planta en su hogar, desconociendo dato alguno sobre su toxicidad, pero que tras un episodio de alergia grave luego de estar en contacto con la misma decidió retirarla. La entrevistada agregó que si bien nunca estuvo del todo segura de que la planta haya sido el origen del inconveniente (incluso el médico que la atendió atribuyó la causa a otra circunstancia), por comentarios de conocidos, posteriores al cuadro presentado, que referían que se trataba de una especie peligrosa para los niños y animales, decidió no tenerla nunca más.

En oposición, otra de las actitudes que se documentó fue la de aquellas personas que cultivan a este tipo de plantas a pesar de ser tóxicas. Estos individuos pueden dividirse en dos grupos: aquellos que las cultivan en cualquier circunstancia y aquellos que lo hacen bajo determinadas condiciones. El primer caso se corresponde, por ejemplo, con el de un entrevistado muy interesado en las plantas nativas, quien opta por cultivarlas independientemente de su toxicidad por tener un concepto positivo sobre las mismas. Como él mismo mencionó: "por más que una especie sea tóxica la cultivaría si se tratase de una autóctona". Por el contrario, las personas del segundo grupo tienen en cuenta la gravedad 


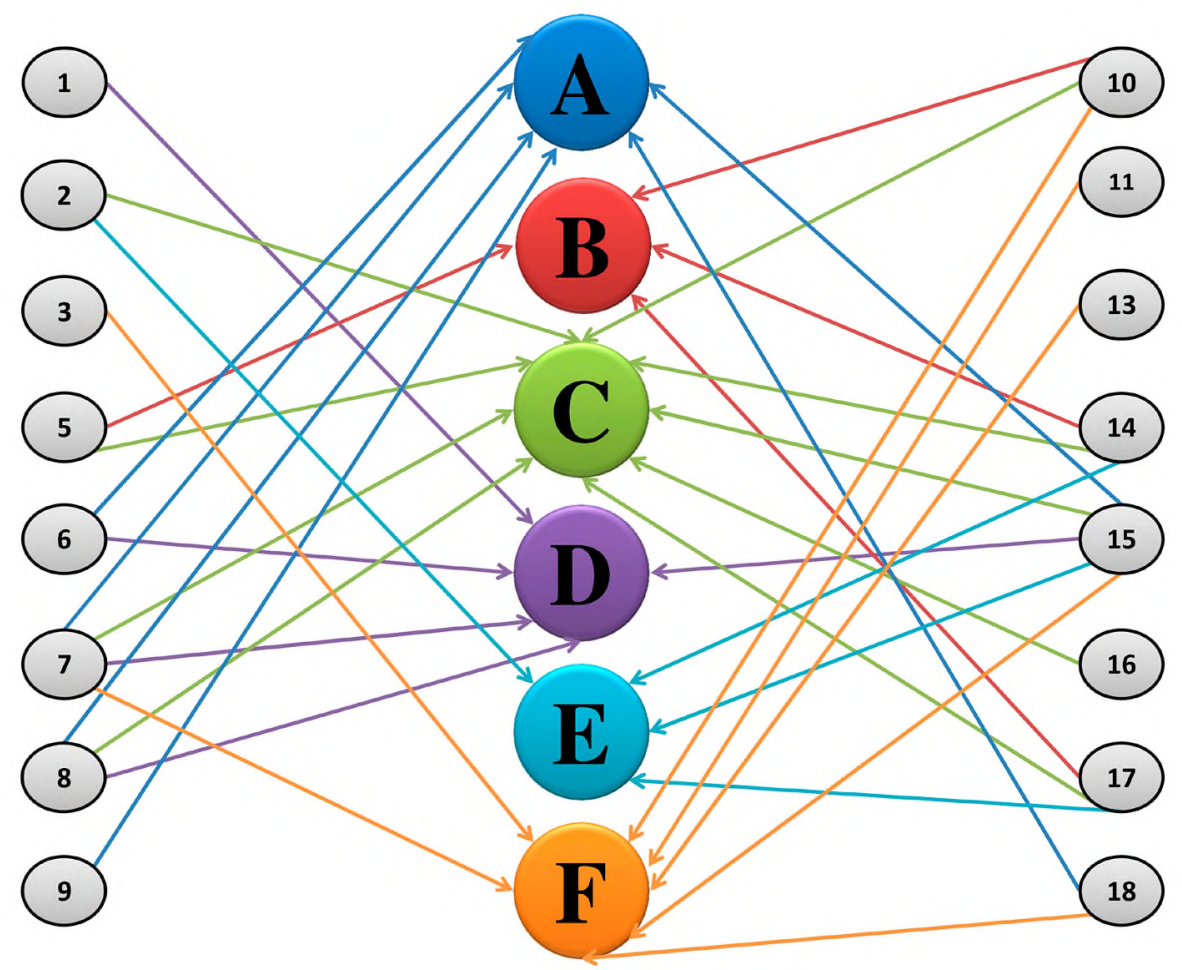

Fig. 3. Criterios A - F utilizados por los entrevistados (1-18). Criterios: A: Compuestos químicos como agente causal del efecto nocivo. B: Cantidad de material vegetal necesario para que ocurra el efecto nocivo. C: Cantidad de personas que logra afectar. D: Severidad del efecto nocivo. E: Probabilidad de ejercer el efecto nocivo. F: Utilidad de la planta. Fig. 3. Criteria $A-F$ used by the interviewees (1-18). Criteria: $A$ : Chemical compounds as the causal agent of the harmful effect. B: Amount of plant material necessary for the harmful effect to occur. C: Number of people that its capable to affect. D: Severity of the harmful effect. E: Probability of exerting the harmful effect. F: Utility of the plant

del efecto producido o el mecanismo de acción de estas especies en conjunto con el contexto doméstico donde habitan. De esta forma, solo las cultivan en caso de que produzcan erupciones cutáneas leves o que actúen por ingesta, considerando en estos casos que no representan una amenaza para ningún miembro de su familia. Aun así, uno de los entrevistados aclaró que ciertas plantas como el "floripondio" no las tendría en su vivienda si tuviese niños pequeños o animales, quienes podrían ingerirla sin intención.

\section{Discusión}

Las familias botánicas más representativas (Solanaceae, Apocynaceae, Euphorbiaceae, Araceae y Aristolochiaceae) son todas muy conocidas en el ámbito académico por presentar compuestos capaces de ocasionar efectos tóxicos (cf. Hashimoto et al., 1999; Burrows et Tyrl, 2013; Nelson et Balick, 2020), por lo que en este aspecto los resultados no llaman la atención. Además, es interesante notar que para la mayoría de las especies existe en la literatura académica un amplio registro de antecedentes respecto de los efectos tóxicos de las distintas partes referidas por los entrevistados para cada mecanismo de acción (Tabla 2). Sin embargo, para algunas especies los datos encontrados sobre toxicidad remiten solo a algunas partes, mecanismos y/o efectos; en otros casos solo se encuentran datos para especies emparentadas, mientras que en otros se carecen por completo de reportes. Así, para la "difenbaquia", el "falso cafeto" (Manihot grahamii Hook.), la "lantana" y el "paraíso", no fue posible hallar 
antecedentes en relación a algunos de los efectos documentados (Tabla 2). Por otra parte, el "azarero" [Pittosporum tobira (Thunb.) W. T. Aiton] es descripto por Filmer (2012) como una planta con elevada toxicidad, si bien refiere para Pittosporum spp. exclusivamente el mecanismo de acción por ingesta, mas no a mecanismos alternativos, como la inhalación o el contacto, los cuales sí han sido mencionados por los entrevistados (Tabla 2). En el caso del "lúpulo silvestre" [Humulus scandens (Lour.) Merr.], el "falso cafeto", el "jazmín de monte" (Psychotria carthagenensis Jacq.) y uno de los "duraznillo negro" (Cestrum euanthes Schltdl.) no se han podido encontrar datos concretos sobre la toxicidad de las partes reportadas, aun cuando sí existen antecedentes respecto a especies emparentadas (Humulus lupulus L., Manihot esculenta Crantz, Psychotria viridis Ruiz \& Pav., Cestrum parqui) (Tabla 2). Por último, para el "nim nim" [Acmella decumbens (Sm.) R. K. Jansen] se carece por completo de información al respecto.

Lo antepuesto sugiere que sería interesante profundizar en los aspectos tóxicos de las especies menos estudiadas a nivel toxicológico, sobre todo teniendo en consideración que se corresponden con especies nativas y/o naturalizadas de los distintos espacios públicos del área de estudio. Al respecto, la información recabada en este trabajo podría ser un buen punto de partida para ello.

En relación a los valores de $\mathrm{C}_{\mathrm{sp}}$ (concensos por especie), se puede ver que el conocimiento en torno a las plantas tóxicas se encuentra poco consensuado a nivel general, presentando valores relativamente bajos, incluso en las especies de mayor consenso (Tabla 2). De igual forma, se observa que en todos los casos el $\mathrm{C}_{\mathrm{pv}-\mathrm{e}}$ (consenso por parte vegetal-efecto) es inferior al $\mathrm{C}_{\mathrm{sp}}$, incluso para las especies de mayor $\mathrm{C}_{\mathrm{sp}}$, lo que indica que no solo el conocimiento sobre las plantas tóxicas se encuentra poco consensuado, en términos generales, sino que además se encuentra disperso aún dentro de las especies más conocidas (Tabla 2). Todo esto puede estar en consonancia con el contexto pluricultural en el que se trabajó, que implica que los habitantes de la zona tienen distintas procedencias $u$ orígenes $y$ por ende es muy probable que presenten diferencias en cuanto a la flora conocida $\mathrm{y}$, además, que su conocimiento proviene de fuentes muy diversas que van desde los medios masivos de comunicación (televisión e internet) hasta los programas de educación formal o informal, los conocimientos ligados a tradiciones y la propia experiencia (Hurrell, 2014; Hurrell et Pochettino, 2014). Al respecto, el entrevistado de nacionalidad paraguaya fue el único que destacó como tóxico al "jazmín paraguayo" (Brunfelsia australis Benth.), una planta que, según describió, se desarrolla espontáneamente en su lugar de origen y que es conocida por producir intoxicaciones en el ganado, en tanto los 3 entrevistados de nacionalidad peruana fueron los únicos que dieron cuenta de la toxicidad de la "estrella federal" (Euphorbia pulcherrima Willd. ex Klotzsch), destacando que se trata de una especie muy conocida por su toxicidad en sus lugares de nacimiento (Tabla 2). Así, aun cuando ambas especies se encuentran presentes en la zona de estudio, ya que son cultivadas como ornamentales, la mayoría de los entrevistados, que son de nacionalidad argentina, desconocen su toxicidad. Esto demuestra que los casos mencionados se corresponden con conocimientos ligados a tradiciones (Hurrell, 2014), intimamente vinculados a los conocimientos locales de sus lugares de origen.

En relación a los programas de educación en torno a las plantas tóxicas, que tenderían a homogeneizar el conocimiento en la temática, se destaca que en el área de estudio son al parecer inexistentes. Adicionalmente, el tipo de información a la que cada persona accede a través de los medios masivos depende mucho de los intereses personales, los cuales pueden variar incluso entre "amantes de las plantas". Tal es así que algunas especies como el "rhus" [Toxicodendron succedaneum (L.) Kuntze] solo fueron mencionadas por entrevistados que son profesores de bonsái, en tanto se trata de especies aptas para este fin, y sobre las cuales aprendieron por leer información en internet. Del mismo modo, personas interesadas en las especies nativas de la región rioplatense se informan principalmente sobre las mismas, lo que los lleva a conocer más sobre su toxicidad que sobre la de otras especies, como ocurrió 
con las del género Aristolochia o con los "duraznillo negro" (Cestrum spp.).

Por último, otra forma de adquirir el conocimiento, y que podría llevar a que el mismo se encuentre disperso, es la experiencia personal, la cual también estaría en gran parte vinculada a las profesiones o a los intereses de cada individuo. Así, los profesores de bonsái han tenido varias experiencias mientras "trabajaban" las plantas (i.e. realizaban técnicas de poda, alambrado, etc.), como les ha sucedido con el "azarero", el "laurel de jardín" o el "tejo" (Taxus baccata L.), mientras que los amantes de las plantas autóctonas han tenido episodios con diversas especies asilvestradas que comparten el ambiente con éstas, como la "oreja de elefante" y el "falso cafeto", mientras realizaban tareas de mantenimiento en la Reserva Ecológica de Vicente López.

Con respecto a las especies con mayores consensos $\left(\mathrm{C}_{\mathrm{sp}} \geq 27,8 \%\right.$ ) (Tabla 2$)$, estas están bien representadas en la zona de estudio. Varias se encuentran muy presentes en los hogares, plazas y parques, y/o forman parte del arbolado urbano, donde son cultivadas como ornamentales, como el "floripondio", el "laurel de jardín", la "difenbaquia" y el "paraíso" (Lahitte et al., 1999, obs. pers. F. Valerio; Hurrell et Bazzano, 2003) (Fig. 2). Asimismo, el "ricino", la "cicuta" y el Cestrum parqui crecen abundantemente en áreas abandonadas o en la costa del Río de la Plata, desarrollándose espontáneamente en la zona de estudio (Lahitte et al., 1998; Hurrell et Bazzano, 2003; Hurrell et al., 2007) (Fig. 4). Por otro lado, estas especies comparten el hecho de que son plantas frecuentemente reportadas como tóxicas por la bibliografia y de que son capaces de producir intoxicaciones severas en caso de ser ingeridas por humanos o por otros mamíferos, como en el caso de Cestrum parqui (Filmer, 2012; Barberón et al., 2020; Nelson et Balick, 2020). Por último, el "floripondio", el "ricino" y la "cicuta", son, además, especies muy presentes en el imaginario popular. El "floripondio", la especie con mayor $\mathrm{C}_{\mathrm{sp}}$, es conocida por varios entrevistados por su uso como psicotrópico (al consumirse las flores) que puede provocar, en ocasiones, la muerte. Por su parte, el "ricino" fue recordado en varias oportunidades por ser la planta a partir de la cual se extrae el "aceite de ricino", al cual le atribuyeron propiedades laxantes, mientras que la "cicuta" fue reconocida por su uso como veneno en la antigüedad y principalmente por ser la planta que produjo la muerte de Sócrates. En resumen, todas estas características en conjunto parecerían estar generando, en términos de Hurrell et Pochettino (2014), una mayor visibilización de estas especies con respecto a las demás, lo que a su vez redunda en los mayores consensos. El carácter exótico de la mayoría de estas especies y los principales usos atribuidos a las mismas sugieren, además, la fuerte influencia que la cultura europea tiene con respecto a la temática entre los entrevistados.

En relación al concepto vernáculo de tóxico, es interesante notar que no todas las plantas que dañan son necesariamente tóxicas, y que para que efectivamente lo sean se deben cumplir ciertos criterios vinculados a un conjunto de aspectos. El criterio "a", que tiene en cuenta cuál es el agente causante del efecto nocivo, se encuentra estrechamente vinculado a la definición propuesta por la toxicología para toxicidad, en la cual se afirma que la misma ocurre cuando un agente químico (i.e. compuesto tóxico) produce efectos adversos sobre un órgano (García et al., 2002; Silbergeld, 2012). Esta noción excluye a los posibles daños ocasionados por lesiones de tipo mecánico, ejemplo que fue brindado por los entrevistados. De igual forma, el criterio " $b$ " establece que todo en cantidades excesivas puede ocasionar un daño, considerando tóxicas solo a aquellas especies capaces de producir el efecto en cantidades reducidas. Esta idea también está presente en la toxicología: "potencialmente casi todas las sustancias conocidas pueden provocar un daño y/o la muerte si están presentes en el organismo en una cantidad suficiente" (García et al., 2002). Sin embargo, las definiciones académicas clasifican a las sustancias en grados de toxicidad (desde prácticamente no tóxico a supertóxico) en función de la cantidad de principio activo necesario para provocar el efecto (Silbergeld, 2012; Pope et al., 2020). Por el contrario, los entrevistados clasifican, excluyentemente, a las plantas en "tóxicas" o "no tóxicas" en función de la cantidad de 
material involucrado en términos relativos (cantidades bajas o cantidades altas).

Dejando el criterio "c" para más adelante, se hace foco ahora en el " $d$ ", aquel que clasifica a las plantas tóxicas como aquellas que producen efectos de gravedad. Una vez más, este concepto encuentra correlación con la clasificación toxicológica y el concepto de dosis, siendo sustancias químicas potentes o muy tóxicas aquellas que provocan efectos de alta intensidad o gravedad (Silbergeld, 2012). En este sentido, y aun cuando los entrevistados no han hecho alusión directa a que las ideas de dosis y severidad se encuentran asociadas, se observa que el criterio "d" estaría considerando como tóxicas sólo a aquellas especies "muy tóxicas" en términos toxicológicos, excluyéndose a aquellas que producen efectos leves.

Hasta aquí, parecería que los criterios "a", "b" y "d" se encuentran íntimamente vinculados; parte de esto se refleja en la Fig. 3, donde se observa que casi todos los entrevistados que utilizaron el criterio " $\mathrm{d}$ " también han hecho uso del "a" (4/5).

Por su parte, el criterio "c", en contraposición a los criterios anteriores, relativiza el efecto dañino en función de la persona afectada en lugar de enfocarse en las características propias de la planta/sustancia (como el tipo de agente causal o la cantidad). El criterio plantea que para que una especie sea considerada tóxica debe poder afectar a todas o a la mayoría de las personas, excluyendo a aquellas especies que provocan reacciones en individuos con predisposiciones o sensibilidades particulares ( $p$. ej. personas alérgicas, mujeres embarazadas). El efecto negativo que puede tener una planta o sustancia en determinados individuos que presentan sensibilidad es abarcado, a nivel científico, por la rama de la inmunotoxicología, que estudia los efectos no deseados que se producen como resultado de la interacción de xenobióticos con el sistema inmunitario (Silbergeld, 2012; Göney et Yalçın, 2017), ampliando el concepto de toxicidad a la interacción entre las características de la especie tóxica y las características del organismo receptor. El criterio "c", en cambio, pone el foco exclusivamente en las características del individuo afectado, en su sensibilidad a las sustancias, dejando a un lado las propiedades del vegetal y las interacciones entre organismos. Este criterio fue el mayormente explicitado por los entrevistados (9/18), lo cual denota su importancia como criterio de diferenciación entre plantas tóxicas y no tóxicas (Fig. 3).

Respecto al criterio "e", que refiere a la probabilidad que tiene la planta tóxica de ejercer el efecto nocivo, este encuentra paralelismos con el concepto de "peligro" en toxicología, definido como "la posibilidad de que la toxicidad sea efectiva en un contexto y situación determinados" (Silbergeld, 2012). Al respecto, García et al. (2002) han destacado que, en situaciones prácticas, es decir, en situaciones en que se manipulan o se interactúa con elementos tóxicos, lo importante es el riesgo o peligro asociado con el uso de la sustancia y no su toxicidad intrínseca. Por oposición, la "seguridad" es la probabilidad de que no exista daño bajo condiciones específicas (García et al., 2002; Pope et al., 2020). Así, en base a esta idea, y dependiendo de las condiciones en las que se utiliza, un compuesto muy tóxico puede ser menos peligroso que uno relativamente no tóxico. La noción de peligro planteada parecería tener una fuerte injerencia entre los entrevistados que emplean el criterio "e", que tiene en cuenta el contexto en el que la especie tóxica y el individuo receptor interactúan, siendo este la clave de que se produzcan o no situaciones de exposición y, por ende, toxicidad en sí.

Por último, el criterio " $f$ " es aquel que no concibe como tóxicas a determinadas plantas que, aun pudiendo ocasionar un daño, presentan usos medicinales o alimenticios que se consideran beneficiosos para la salud. Este criterio pone así en contraposición las ideas de efecto saludable, por un lado, y efecto tóxico por el otro, en relación a una misma especie; cuando el primero existe, el segundo queda soslayado. Una vez más, si se repasan algunas de las definiciones anteriores, se puede apreciar que para la toxicología estas dos ideas están relacionadas al concepto de dosis, ya que variaciones en la misma pueden originar que un efecto medicinal se convierta en uno tóxico (García et al., 2002). De esta forma, para la ciencia académica una especie puede ser tóxica y medicinal a la vez, pero entre los 
entrevistados que emplearon este criterio es, de forma excluyente, una u otra cosa. Este criterio fue el segundo más explicitado por los entrevistados, lo que denota la directa asociación de la idea de tóxico con perjudicial en contrapartida con la idea de beneficioso.

Teniendo en cuenta todo lo discutido, se aprecia que no existe un único concepto o definición vernácula sobre plantas tóxicas, aun cuando existen criterios que son más compartidos que otros. Además, varios de estos criterios encuentran paralelismos con las definiciones clásicas de la toxicología o de campos disciplinares relacionados. Lo expuesto se encuentra de acuerdo a lo previsto para el conocimiento botánico en contextos urbanos, donde el mismo es heterogéneo $\mathrm{y}$, al menos en parte, se halla ligado al conocimiento científico occidental (Hurrell et Pochettino, 2014).

Para finalizar, en base a las actitudes registradas de los entrevistados para con las plantas tóxicas se deducen tres tipos de posturas, estas son: a) evitarlas; b) cultivarlas; c) posición intermedia. Las primeras dos son acciones opuestas, pero que comparten el hecho de que pareciera no haber premeditación antes de decidir si no-cultivar/erradicar una planta que saben que es tóxica, o cultivarla/ mantenerla más allá de que lo sea. Por su parte, la tercera postura fue denominada "posición intermedia", ya que puede derivar en alguna de las otras dos posturas, dependiendo de la persona, pero siempre en base a una premeditación, es decir que existe una evaluación previa de la situación antes de tomar una decisión.

La primera postura, "evitar las plantas tóxicas", es la que adoptan aquellas personas que optan por no cultivar las plantas que les informan que son tóxicas, como sucedió, por ejemplo, con los que rechazaron el "duraznillo negro" o el "floripondio" o con la que erradicó la "difenbaquia". Este tipo de reacción indica que las personas advierten un peligro en estos casos, en especial por desconocer pormenores sobre la toxicidad de las especies, como partes, efectos y mecanismos por los cuales estas tienen efecto. Así, esta advertencia de peligro inminente excluye la posibilidad de que estas plantas sean aptas para estar presentes en el espacio doméstico, según estas personas.

La segunda postura, "cultivarlas aunque sean tóxicas", es la de un entrevistado aficionado a las plantas nativas, que las considera beneficiosas para el ecosistema por el rol particular que cada especie juega en él, motivo que lo lleva a querer cultivarlas más allá de que puedan representar algún peligro. Así, la valoración positiva de estas plantas es un factor que supera, en este caso, las características negativas que presenta, es decir, su toxicidad. Situaciones similares a las reportadas por este entrevistado podrían suceder a menudo con los amantes de las plantas en general, quienes muchas veces por el hecho de querer proteger y/o tener en sus hogares una determinada especie, quizás no se detienen a analizar las consecuencias negativas que podrían ocasionar si no se las maneja adecuadamente. De esta forma, en estos casos podría suceder que se cultiven plantas tóxicas a las que estén expuestos los niños o animales y que esto derive en intoxicaciones accidentales, tal como señalan Nelson et Balick (2020) y Pérez Cuadra et al. (2012).

La tercera y última postura, "posición intermedia", es la de aquellos entrevistados que poseen plantas en su jardín que saben que son tóxicas, pero analizan diversas variables antes de tomar una actitud al respecto. Algunos ejemplos son el del entrevistado que mantiene a la "lantana", ya que la dermatitis que le ocasiona es leve, y el de aquel que conserva a la "azalea" porque conoce el mecanismo de acción y considera que no representa un peligro para los integrantes de la familia. Vale remarcar, sin embargo, que esta última persona sostuvo que si se encontrase en otro contexto familiar (p. ej. si tuviera hijos pequeños) podría no cultivar o erradicar algunas plantas por considerarlas peligrosas.

De estas tres posturas, en la primera parecería que prevalece el temor sobre todo, mientras que en la segunda, en cambio, predomina la falta de recaudos o precaución. A los fines de preservar la salud humana y la flora al mismo tiempo, la postura intermedia parecería ser entonces la más conveniente: al contar con información sobre los pormenores de la toxicidad de las especies se puede realizar un manejo crítico y consciente. Es posible que la postura de las personas que optan por 
"evitarlas" cambie a una postura del tipo "intermedia" si dispusieran de información precisa (parte tóxica, mecanismo de acción, efecto, etc.) que les permitiese evaluar y decidir en consecuencia. Esto mismo también sería importante para aquellos que adoptan la postura "cultivar", ya que si de todos modos van a tener la planta sería recomendable que sepan qué recaudos básicos tener. En base a lo dicho, y dado que el acceso a esa información es limitado, en particular para la zona de estudio, la generación de materiales y programas de difusión en la temática constituyen el primer paso a ejecutar para lograr lo anterior.

\section{Conclusiones}

En esta primera prospección sobre la etnobotánica de plantas tóxicas en Vicente López se identificaron 42 especies consideradas tóxicas por los entrevistados, quienes reportaron partes y mecanismos diversos que producen efectos de distinta gravedad. Para la mayoría de estas especies existen reportes en la literatura académica que coinciden con los datos brindados por los entrevistados. Sin embargo, gran parte de las especies para las que no se hallaron dichos reportes son nativas de la región o están naturalizadas. Los aportes de este trabajo pueden ser una base concreta para abordar investigaciones que profundicen en los aspectos toxicológicos de las mismas.

Los consensos sobre la toxicidad de las especies mencionadas, y más aún los consensos sobre los efectos que producen las partes de esas plantas, son bajos en general. Solo 7 de las 42 especies presentaron consensos por especie mayores a $27,8 \%$, sin superar el $50,0 \%$, de las cuales 6 son exóticas, y los consensos por parte-efecto no superan el 38,9\%. Además, se concluye que no existe un único concepto vernáculo de planta tóxica. Los entrevistados utilizan alternativamente un conjunto de criterios para clasificar a una especie como tóxica, que en general encuentran paralelismos con definiciones de la toxicología. Por último, las personas adoptan diferentes posturas cuando se encuentran ante una planta que consideran tóxica: la evitan, la conservan o cultivan de todos modos, o toman una decisión sobre qué hacer basándose en el conocimiento sobre su toxicidad y considerando el contexto en el que se encuentra (p. ej. potencial peligro para niños o mascotas).

La heterogeneidad de la información hallada, así como la concordancia, al menos en parte, con el conocimiento científico occidental, está en consonancia con las particularidades del contexto pluricultural en el cual se desarrolló el estudio, con personas de distintos orígenes $\mathrm{y}$ variabilidad de formas y posibilidades de adquisición de la información sobre plantas tóxicas, que es lo previsto para el CBU.

En este escenario, teniendo en cuenta que para conservar la salud y la flora local es necesario que la gente haga un manejo responsable de las plantas tóxicas, resulta imprescindible que se generen y promuevan programas educativos sobre la temática, hoy inexistentes. Para ello, no solo es importante difundir a la población información certera sobre los pormenores de la toxicidad de las especies, sino que es clave conocer cuáles son los conocimientos, representaciones y actitudes de la gente para con estas plantas, ya que esto determinará el éxito de los proyectos de trabajo con la comunidad, a lo cual se contribuye con este artículo.

\section{Agradecimientos}

A las personas entrevistadas, que tan amablemente compartieron con nosotros sus experiencias, sentimientos y saberes sobre la vegetación local y nos permitieron, en muchos casos, acceder a sus hogares. A Mariana Valente, por el diseño y confección de las láminas y el mapa. A los/las revisores/ as anónimos/as que hicieron aportes valiosos al manuscrito.

\section{Bibliografía}

Albuquerque, U. P., Da Cunha, L. V. F. C., De Lucena, R. F. P. y Alves, R. R. N. (eds.) (2014). Methods and techniques in ethnobiology and ethnoecology. Humana Press, Nueva York.

Alonso, J. \& Desmarchelier, C. (2015). Plantas medicinales autóctonas de la Argentina. Bases 
científicas para su aplicación en atención primaria de la salud. Corpus Libros Médicos y Científicos, Buenos Aires.

Arenas, P. \& Martínez, G. (2012). Estudio etnobotánico en regiones áridas y semiáridas en Argentina y zonas limitrofes. Experiencias y reflexiones metodológicas de un grupo de investigación. En Arenas, P. (ed.), Etnobotánica en Zonas Áridas y Semiáridas del cono sur de Sudamérica, pp. 11-14. CEFYBO-CONICET, Buenos Aires.

Ashafa, A. O. T., Sunmonu, T. O. \& Afolayan, A. J. (2010). Toxicological evaluation of aqueous leaf and berry extracts of Phytolacca dioica L. in male Wistar rats. Food and Chemical Toxicology 48: 1886-1889.

Barberón, J., Gambaro, R., Padula, G., Seoane, A., Ventura, B., Leaden, M., Palacios, A. \& Zeinsteger, P. (2020). Effects of a leaf extracts from the poisonous plant Cestrum parqui $\mathrm{L}$. 'Herit ("duraznillo negro", Solanaceae) on genotoxicity. Toxicon 177: S50. https://doi.org/10.1016/j.toxicon.2019.12.104

Burrows, G. E. \& TyrL, R. J. (2013). Toxic plants of North America. John Wiley \& Sons, Iowa.

Califano, L. M. \& Echazú, F. (2013). Etnobotánica en comunidades pastoriles. Conocimiento tradicional sobre especies tóxicas para el ganado en la cuenca del río Iruya (Salta, Argentina). Boletín de la Sociedad Argentina de Botánica 48: 365-375. https://doi.org/10.31055/1851.2372.v48.n2.6271

Cariñanos, P. \& CASAREs-Porcel, M. (2011). Urban green zones and related pollen allergy: a review. Some guidelines for designing spaces with low allergy impact. Landscape and Urban Planning 101: 205-214. https://doi.org/10.1016/j.landurbplan.2011.03.006

Chakraborty, S., Siegenthaler, J. \& BüChi, E. R. (1995). Corneal edema due to Asclepias curassavica. Archives of Ophthalmology 113: 974-975.

https://doi.org/10.1001/archopht.1995.01100080024013

Doan, U. V., Wu, M. L., Phua, D. H., Mendez Rojas, B. \& YANG, C. C. (2019). Datura and Brugmansia plants related antimuscarinic toxicity: an analysis of poisoning cases reported to the Taiwan poison control center. Clinical Toxicology 57: 246-253.

Filmer, A. K. (2012). Safe and poisonous garden plants. Disponible: https://ucanr.edu/sites/poisonous_safe_ plants/ (Consulta 12/06/2021)

Freire, S. E., Arambarri, A. M., Bayón, N. D., Sancho, G., Urtubey, E., Monti, Novoa M. C. \& Colares, M. N. (2005). Epidermal characteristics of toxic plants for cattle from the Salado river basin (Buenos
Aires, Argentina). Boletín de la Sociedad Argentina de Botánica 40: 241-281

Gaig, P., Gázquez, V., Lombardero, M., Botey, E. \& García Ortega, P. (2005). Moth plant (Araujia sericifera) allergy. Allergy 60: 1092-1093. https://doi.org/10.1111/j.1398-9995.2005.00859.x

García, J. A., Cantón, G. J., García, B. L., Micheloud, J. F., CAmpero, C. M., Späth, E. J. \& Odriozola, E. R. (2017). Retrospective analysis of cattle poisoning in Argentina (2000-2013). Pesquisa Veterinária Brasileira 37: 210-214. https://doi.org/10.1590/s0100-736×2017000300002

García, E., Valverde, E., Agudo, M. A., Novales, J. \& LuQue M. I. (2002). Toxicología clínica. En Gamundi Planas, M. C. (coord.), Farmacia Hospitalaria - Tomo 1, pp. 667-710. Sociedad Española de Farmacia Hospitalaria, Madrid.

GöNEY, G. \& YALÇIN, A. D. (2017). Immunotoxicity of allergens. Journal of Allergy \& Therapy 8: 1-6.

Hashimoto, K., Higuchi, M., Makino, B., Sakakibara, I., Kubo, M., Komatsu, Y., Maruno, M. \& Okada, M. (1999). Quantitative analysis of aristolochic acids, toxic compounds, contained in some medicinal plants. Journal of Ethnopharmacology 64: 185-189. https://doi.org/10.1016/S0378-8741(98)00123-8

Huar, H. (2010). Ethnomedicinal analysis of toxic plants from five ethnic groups in China. Ethnobotany Research and Applications 8: 169-179. https://doi.org/10.17348/era.8.0.169-179

Huat, H. \& Xu, J. (2000). Indigenous knowledge: an inexhaustible "information bank" for toxin research. Toxicon 38: 745-746. https://doi.org/10.1016/S0041-0101(99)00150-6

HurRell, J. A. (2014). Urban ethnobotany in Argentina: theoretical advances and methodological strategies. Ethnobiology and Conservation 3: 1-11. https://doi.org/10.15451/ec2014-6-3.3-1-11

Hurrell, J. A. \& Bazzano, D. H. (2003). Arbustos 1: nativos y exóticos. Biota Rioplatense VIII. L.O.L.A, Buenos Aires.

Hurrell, J. A., Bazzano, D. H. \& Delucchi, G. (2005). Monocotiledóneas herbáceas: nativas y exóticas. Biota Rioplatense X. L.O.L.A, Buenos Aires.

Hurrell, J. A., Bazzano, D. H. \& Delucchi, G. (2007). Dicotiledóneas herbáceas 2: nativas y exóticas. Biota Rioplatense XII. L.O.L.A, Buenos Aires.

Hurrell, J. A. \& Pochettino, M. L. (2014). Urban ethnobotany: theoretical and methodological contributions. En AlbuQuerque, U. P., Cruz da Cunha, L.V. F., Paiva de Lucena, R. F. \& R. R. Nóbrega Alves (eds.), Methods and techniques 
in ethnobiology and ethnoecology, pp. 293-309. Humana Press, Nueva York.

Isbister, G. K., OAKley, P., Dawson, A. H. \& Whyte, I. M. (2003). Presumed Angel's trumpet (Brugmansia) poisoning: clinical effects and epidemiology. Emergency Medicine 15: 376-382. https://doi.org/10.1046/j.1442-2026.2003.00477.x

Jankowski, L. S., Bazzano, D., Sáenz, A. A., Tourn, M. \& Roitman, G. (2000). Plantas trepadoras: nativas y exóticas. Biota Rioplatense V. L.O.L. A, Buenos Aires.

Jayawickreme, K. P., Janaka, K. V. C. \& Subasinghe, S. A. S. P. (2019). Unknowing ingestion of Brugmansia suaveolens leaves presenting with signs of anticholinergic toxicity: a case report. Journal of Medical Case Reports 13: 1-4. https://doi.org/10.1186/s13256-019-2250-1

Lahitte, H. B., Hurrell, J. A., Belgrano, M. J., Jankowski, L. S., Haloua, M. P. \& Mehltreter, K. (1998). Plantas medicinales rioplatenses. L.O.L.A., Buenos Aires.

Lahitte, H. B., Hurrell, J. A., Valla, J. J., Jankowski, L., Bazzano, D. \& Hernández, A. J. (1999). Árboles urbanos: inventario temático de la biota de la región del Delta del Paraná, Isla Martín García y Ribera Platense. Biota Rioplatense IV. L.O.L.A., Buenos Aires.

Lord, J. M. \& Hartley, M. R. (eds.) (2010). Toxic plant proteins. Springer Science \& Business Media, Londres.

Mandrile, E. \& CAFrerata, L. F. (1993). Cromatografía en Fase Gaseosa y Acción Farmacodinámica de los Compuestos Volátiles del "Mataojo" (Pouteria salicifolia (Spreng.) Radlk.). Acta Farmacéutica Bonaerense 12: 5-14.

Martínez, G. J. \& Luján, M. C. (2011). Medicinal plants used for traditional veterinary in the Sierras de Córdoba (Argentina): an ethnobotanical comparison with human medicinal uses. Journal of Ethnobiology and Ethnomedicine 7: 1-19.

https://doi.org/10.1186/1746-4269-7-23

Matteucci, S. D. (2012). Ecorregión Delta e Islas de los ríos Paraná y Uruguay. En Morello, J., Matteucci, S. D., Rodríguez, A. \& Silva, M. E. (eds.), Ecorregiones y complejos ecosistémicos argentinos, pp. 447-488. Orientación Gráfica, Buenos Aires.

Modi, G. M., Doherty, C. B., Katta, R. \& Orengo, I. F. (2009). Irritant contact dermatitis from plants. Dermatitis 20: 63-78.

https://doi.org/10.2310/6620.2009.08051
Nelson, L. \& BALICK, M. (2020). Handbook of poisonous and injurious plants. New York Botanical Garden and Springer, Suiza.

https://doi.org/10.1007/978-1-4939-8926-3

Observatorio AMBA (2021). Partido de Vicente López. Disponible: http://www.observatorioamba.org/ planes-y-proyectos/partidos-rmba/vicente-lopez (Consulta 12/06/2021)

Peate, W. F. (2007). Work-related eye injuries and illnesses. American Family Physician 75: 1017-1022.

Pérez Cuadra, V., Cambi, V., Rueda, M. A. \& Calfuán, M. (2012). Consequences of the loss of traditional knowledge: the risk of injurious and toxic plants growing in kindergartens. Ethnobotany Research and Applications 10: 77-94.

https://doi.org/10.17348/era.10.0.077-094

Phua, D. H., Tsai, W. J., Ger, J., Deng, J. F. \& Yang, C. C. (2008). Human Melia azedarach poisoning. Clinical Toxicology 46: 1067-1070. https://doi.org/10.1080/15563650802310929

Pope, C. N., Schlenk, D. \& BaUd, F. J. (2020). History and basic concepts of toxicology. En PoPE, C. N. \& J. LIU (eds.), An introduction to interdisciplinary toxicology: from molecules to man, pp. 3-15. Academic Press, Londres.

https://doi.org/10.1016/B978-0-12-813602-7.00001-6

Rivero, R., Adrien, M. L., Matto, C., Novoa, F., Uriarte, G. \& Charbonier, D. (2010). Intoxicación por Wedelia glauca en bovinos en Uruguay. Veterinaria (Montevideo) 46: 39-45.

Roger, E., Palacio, M., Coria, O. \& Díaz, R. (2016). Notas sobre la flora urbana cultivada en la ciudad de Santiago del Estero, Argentina. Multequina 25: 1-16.

Rovere, A. E., Molares, S. \& Ladio, A. H. (2013). Plantas utilizadas en cercos vivos de ciudades patagónicas: aportes de la etnobotánica para la conservación. Ecología Austral 23: 165-173.

https://doi.org/10.25260/EA.13.23.3.0.1171

Santos, K. S., Galvao, C. E., Gadermaier, G., Resende, V. M. F., de Oliveira Martins, C., Misumi, D. S., Yang, A. C., Ferreira, F., Palma, M. S., Kalil, J. \& CAstro, F. F. M. (2011). Allergic reactions to manioc (Manihot esculenta Crantz): Identification of novel allergens with potential involvement in latex-fruit syndrome. Journal of Allergy and Clinical Immunology 128: 1367-1369. https://doi.org/10.1016/j.jaci.2011.07.019

Schmeiser, H. H., Stiborova, M. \& Arlt, V. M. (2008). Chemical and molecular basis of the carcinogenicity of Aristolochia plants. Current Opinion in Drug Discovery \& Development 12: 141-148. 
Schultes, R., Hofmann, A. \& RäTsch, C. (1998). Plants of the Gods: their sacred, healing, and hallucinogenic powers. Healing Art Press, Lucerna.

Senthil kumaran, S.,Meenakshisundaram, R.,Michaels, A. D. \& Thirumalaikolundusubramanian, P. (2011) Electrocardiographic changes during inhalational oleander toxicity. Journal of Electrocardiology 44: 470-472. https://doi.org/10.1016/j.jelectrocard.2010.12.002

Severino, L. (2009). Toxic plants and companion animals. CAB Reviews: Perspectives in Agriculture, Veterinary Science, Nutrition and Natural Resources 4: $1-6$.

Silbergeld, E. K. (dir.) (2012). Toxicología. En Stellman, J. M. (ed.), Enciclopedia de Salud y Seguridad en el Trabajo OIT - Tomo 1 (sec. 33.133.76). Ministerio de Trabajo y Asuntos Sociales, Subdirección General de Publicaciones, Madrid.

Slaaughter, R., Beasley, M. \& Schep, L. (2017). Dermatitis due to Toxicodendron plants: a common occurrence during autumn. Dermatitis 130: 82-83.

Terblache, M., De Klerk, W. A., Smit, J. D. \& AdelaAR, T. F. (1966). A toxicological study of the plant Sesbania punicea Benth. Journal of the South African Veterinary Association 37: 191-197.

Unlu, U. \& KocAbaş, A. (2020) Dieffenbachia plant poisoning cases and effects on human health. Anatolian Journal of Botany 4: 65-68. https://doi.org/10.30616/ajb.682862

VAlla, J. J., SÁenz, A., Rivera, S. M., Jankowski, L. S. \& Bazzano, D. (2001). Árboles urbanos 2. Biota Rioplatense VI. L.O.L.A, Buenos Aires.

WiCC (WONCA International Classification Committee) (2000). ICPC-2e - International
Classification of Primary Care version 2e. Disponible: https://www.ehelse.no/kodeverk/icpc2e--english-version (Consulta 12/06/2021)

Wilson, C. R., SAUER, J. M. \& Hooser, S. B. (2001). Taxines: a review of the mechanism and toxicity of yew (Taxus spp.) alkaloids. Toxicon 39: 175-185. https://doi.org/10.1016/S0041-0101(00)00146-X

Winks, C. J. \& Fowler, S. V. 2000. Prospects for biological control of moth plant, Araujia sericifera (Asclepiadaceae). Landcare Research Contract Report LC9900/100.

Wittstock, U. \& Gershenzon, J. (2002). Constitutive plant toxins and their role in the defense against hervibores and pathogens. Current Opinion in Plant Biology 5: 300-307.

WFO (2021). World Flora OnLine. Disponible: http://www. worldfloraonline.org (Consulta 12/06/2021).

Worbs, S., Köhler, K., Pauly, D., Avondet, M. A., Schaer, M., Dorner, M. B. \& Dorner, B. G. (2011). Ricinus communis intoxications in human and veterinary medicine - A summary of real cases. Toxins 3: 1332-1372. https://doi.org/10.3390/toxins3101332

Zanoli, P. \& Zavatti, M. (2008). Pharmacognostic and pharmacological profile of Humulus lupulus L. Journal of Ethnopharmacology 116: 383-396. https://doi.org/10.1016/j.jep.2008.01.011

Zeinsteger, P. A., Palacios, A., Barberón, J. L., Zufriategur, L. \& Pernazza Lovey, F. (2016). Intoxicación por Brunfelsia australis en caninos: confirmación mediante identificación del vegetal en muestras biológicas. Revista Veterinaria 27: 51-57. https://doi.org/10.30972/vet.2711077 